\title{
Spatial Competition with Heterogeneous Firms
}

Jonathan Vogel

University of California, Los Angeles

\begin{abstract}
I model endogenous horizontal and vertical product differentiation with arbitrarily many heterogeneous firms. Firms are asymmetric in that they differ in their marginal costs. I prove that under an equilibrium refinement, all economically relevant firm outcomes are uniquely determined across all strict subgame perfect Nash equilibria. There are two central results. First, a firm's price, market share, and profit are independent of its neighbors' marginal costs, conditional on the average marginal cost in the market. Second, more productive firms are more isolated, all else equal. In particular, the distance between two firms is strictly decreasing in their average marginal cost.
\end{abstract}

\section{Introduction}

Product characteristics are typically taken as given when economists study pricing strategies and firm behavior more generally. But firms in industries with product differentiation actually choose the features of their goods. The assumption that firms do not can create endogeneity bias.

As an example, consider estimating the impact on domestic profit of a counterfactual tariff increase. A standard econometric approach estimates the demand system and producers' marginal costs using data

I am indebted to Robert Shimer and to three anonymous referees for their helpful suggestions. I am grateful to participants at numerous seminars, Andrew Atkeson, Vasco Curdia, Wioletta Dziuda, Hugo Hopenhayn, Esteban Rossi-Hansberg, Mark Melitz, Larry Samuelson, Chris Sims, Chad Syverson, and especially Christian Hellwig, Faruk Gul, and Gene Grossman for helpful comments. I acknowledge with thanks the National Science Foundation for support under grants SES 0211748 and SES 0451712. Any opinions, findings, and conclusions or recommendations expressed in this paper are those of the author and do not necessarily reflect the views of the National Science Foundation or any other organization.

[Journal of Political Economy, 2008, vol. 116, no. 3]

(C) 2008 by The University of Chicago. All rights reserved. 0022-3808/2008/11603-0005\$10.00 
on market shares, product characteristics, and prices. In estimating the tariff's effect, an econometrician must assume unchanging product characteristics even in the face of increases in importers' marginal costs. Although it is generally understood that a firm might alter the characteristics of its goods in response to changes in the economic environment, no model predicts how product characteristics might change. This paper solves such a model; the model indicates that the standard approach underestimates the effect of trade policy on domestic profits. In particular, the paper suggests that higher tariffs induce importers to alter product features in order to compete less directly with domestic producers.

This is just one instance of an issue common to a multitude of industrial organization problems. This paper develops and solves a stylized spatial competition model to confront these issues. I consider a twostage game of complete information. A mass of consumers is uniformly distributed through space, where space is represented by a unit circumference. Each consumer inelastically demands one unit of output and purchases from the firm that charges the lowest location-adjusted price (the price the firm charges plus the cost of transportation, borne by the consumer, between the firm's location and the consumer's location). Firms are heterogeneous in that they differ in their constant marginal costs of production. In the first stage, each of a set of heterogeneous firms simultaneously locates in space. ${ }^{1}$ In the second stage, firms simultaneously set their prices.

The model is related to a theoretical spatial competition literature ${ }^{2}$ that encountered difficult technical issues characterizing equilibria in which both prices and locations are endogenous. This paper solves one such issue. A typical approach to solving for a subgame perfect Nash equilibrium (SPNE) in such a game entails solving for equilibria in prices given arbitrary locations. However, d'Aspremont, Gabszewicz, and Thisse (1979) prove that, with linear transportation costs, no pure strategy equilibrium exists to a price stage game (one in which locations are fixed) in which the two firms are located "too closely." The fundamental problem is that profits are not globally quasi-concave. A natural approach is to consider mixed strategy equilibria; unfortunately, this strategy has previously proven intractable (see Osborne and Pitchik 1987). ${ }^{3}$ In this paper I solve for an equilibrium in an auxiliary game that has convenient properties; in particular, there is a pure strategy equilibrium

\footnotetext{
${ }^{1}$ I assume that firms' marginal costs are not too different. This is explained below.

${ }^{2}$ For an excellent survey of spatial competition models with ex ante symmetric firms, see Anderson, de Palma, and Thisse (1992).

${ }^{3}$ Another natural approach is to assume that the cost of transportation is sufficiently convex. I know of no analytic solutions with heterogeneous firms and convex costs of transportation.
} 
in prices given arbitrary locations. Under the restriction that firms' marginal costs are sufficiently similar, I then verify that the equilibrium in the auxiliary game is also an equilibrium in the real game: profit in the auxiliary game provides an upper bound for expected profit in the real game, and profits in the auxiliary and real games are equal along the equilibrium path. The key insight is that once I am able to bound expected profit in the real game with profit in the auxiliary game, I avoid the necessity of solving for a mixed strategy equilibrium in an arbitrary subgame. Using this technique, I prove two main results.

First, within a market, more productive firms are more isolated, all else equal. Hence, the competitors of a very productive firm sell goods that substitute relatively poorly for its goods; this corresponds to more productive firms facing less elastic residual demand curves. This result provides new insight into the mechanisms linking differences in productivity and differences in profit. Within a market, more productive firms have larger market shares for two reasons. First, they charge lower prices. This is a standard result. Second, the direct competitors of relatively productive firms offer consumers relatively poor substitutes. This is a novel result that provides a new rationale for why productive firms set higher markups: they exert greater market power because consumers find it more difficult to substitute away to competitors.

I also prove that if firms incur positive shipping costs, all relevant firm characteristics-price, market share, and profit-are uniquely determined in any strict SPNE (defined below). For any firm, each of these outcomes is a deterministic function of the firm's own marginal cost, the average marginal cost of all firms in the market, and the number of firms in the market. In equilibrium, a firm's price, market share, and profit are independent of its neighbors' marginal costs, controlling for the average marginal cost in the market.

This second result implies that, to the extent that relocation is costless, the impact of a reduction in one firm's marginal cost on a second firm's profit is independent of the number of firms separating the two competitors. Making good policy prescriptions often depends on understanding the extent to which competition is local or global. In the former situation, a product competes directly only with its direct neighbors. In the latter circumstance, a product competes directly with all other products in the market. ${ }^{4}$ My result suggests caution when considering the policy implications of local competition in price setting. To the extent that firms can easily change their locations or the characteristics of their

\footnotetext{
${ }^{4}$ Pinkse, Slade, and Brett (2002), e.g., estimate a flexible price competition model on wholesale gasoline markets in the United States. They find that competition is extremely local.
} 
products, local competition in price setting is consistent with global competition in the location-and-price game.

The remainder of the paper is in four sections. Section II provides the setup of the model. Section III presents a set of SPNE, outlines the structure of the proof, proves that this is the unique set of strict SPNE under a simple refinement, and discusses empirically testing the central comparative static result. Section IV generalizes the model to incorporate vertical as well as horizontal differentiation. Section $\mathrm{V}$ presents conclusions.

\section{Setup}

Consumers.-The market is represented by a unit circumference; locations in the market are indexed by $z \in[0,1)$. There is a mass $L>0$ of consumers who are uniformly distributed along the circumference of the circle. Each consumer buys either one unit of output or no output at all. A consumer located at point $z$ buying a unit of output from firm $i$ derives utility

$$
u(z, i)=v-p_{i}-t \times D(z, i),
$$

where $v$ is the common valuation of output, $p_{i}$ is the price that firm $i$ charges, $D(z, i)$ is the shortest arc length separating consumer $z$ from firm $i$, and $t>0$ is the "transport" cost per unit of distance. Consumer $z$ incurs a utility cost of $t D(z, i)$ if consuming firm $i$ 's variety; this cost is denoted the shopping cost. The shopping cost has two interpretations. In a market in which homogeneous goods are differentiated by the geographic locations of vendors, the shopping cost represents the cost the consumer incurs either transporting the good from the firm or traveling to and from the firm. In a differentiated goods market, the shopping cost represents the utility a consumer loses purchasing a good that differs from her ideal variety.

According to these preferences, if a consumer purchases one unit of output, she buys from the firm with the lowest location-adjusted price, $p_{i}+t D(z, i)$. A consumer who does not purchase any output obtains zero utility. Consumer $z$, in a market with a finite set of producers, $N$, purchases one good from firm $i \in N$ only if

$$
i \in \arg \min _{j \in N}\left\{p_{j}+t D(z, j)\right\} \text { and } p_{i}+t D(z, i) \leq v .
$$

A consumer who is indifferent between two firms' varieties buys from the firm that is closer to her location. I assume throughout that the valuation $v$ is sufficiently high that, given the other parameters of the model, all consumers in the market purchase a good in equilibrium.

Figure 1 graphically represents location-adjusted prices. In figure 1, 


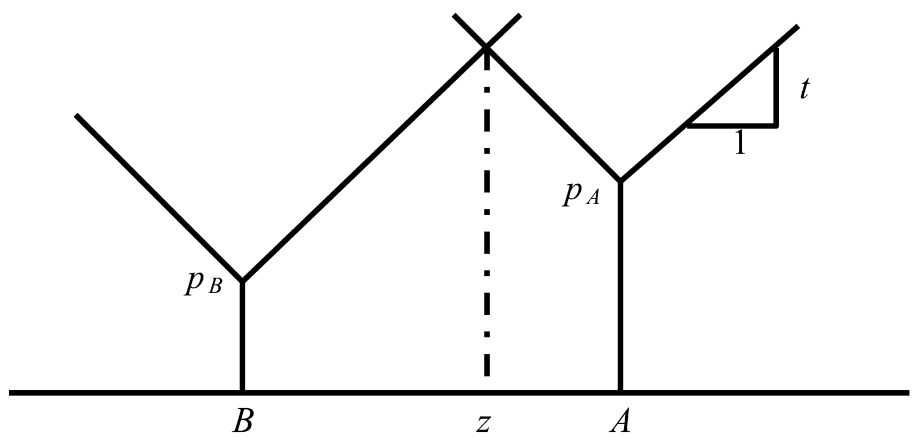

Fig. 1.-Location-adjusted prices and the indifferent consumer

the horizontal line is the circumference of the circle; the heights of the vertical lines are the firms' prices, $p_{A}$ and $p_{B} ; A$ and $B$ represent the firms' locations; and consumer $z$ is the consumer indifferent between purchasing from the two firms. All consumers between firm $B$ and consumer $z$ strictly prefer buying from $B$ rather than from $A$. All consumers between consumer $z$ and firm $A$ strictly prefer buying from $A$ rather than from $B$.

Firms.-There are $n \geq 2$ firms. ${ }^{5}$ Each firm $i$ has a constant marginal cost of production $k_{i} \geq 0$, and $\vec{k}$ denotes the average marginal cost of firms in the market. Additionally, each firm $i$ incurs a variable shipping cost of $2 \tau D(z, i)$ to "ship" a good to a consumer located at a point $z$, where $\tau \in[0, t){ }^{6}$ Firm $i$ 's cost of producing and supplying a consumer located at point $z$ is given by

$$
k_{i}+2 \tau D(z, i) .
$$

The game.-There are $n \geq 2$ firms that play a two-stage game of complete information. In the first stage, the location stage, firms simultaneously choose locations on the circumference of the circle $z_{i} \in[0$, $1)$, where $\mathbf{z} \equiv\left(z_{0}, \ldots, z_{n-1}\right)$. In the second stage, the price stage, firms observe locations and simultaneously choose their prices $p_{i} \in[0, \infty]$, where $\mathbf{p} \equiv\left(p_{0}, \ldots, p_{n-1}\right) .^{7}$ A pure strategy is a choice of location and a mapping from locations, $\mathbf{z}$, into prices. A strategy for firm $i, \omega_{i}$, specifies a probability distribution over locations and a probability distribution

${ }^{5}$ Throughout, I index the $n$ firms $0,1, \ldots, n-1$. I do this in order to define vectors as modular using the standard notation.

${ }^{6}$ The shipping cost $\tau$ is included to generate an equilibrium refinement. All results hold, excluding uniqueness, if $\tau=0$. In all that follows I always indicate which results depend on the shipping cost being strictly positive. I discuss this assumption further below.

${ }^{7}$ The assumption that firms choose their physical locations before their prices is realistic. A producer must design its product and a retailer must build a store. These "location" investments are fixed at the time that firms make their pricing decisions. 
over prices as a function of locations. ${ }^{8}$ Denote firm $i$ 's strategy space by $\Omega_{i}$. Let $\Omega^{n} \equiv \Omega_{0} \times \cdots \times \Omega_{n-1}$ and let $\boldsymbol{\omega} \in \Omega^{n}$ be a strategy vector.

Let $\vartheta(\mathbf{z}, \mathbf{p})$ be the set of locations at which consumers buy from firm $i$. Firm $i$ 's profit from selling to the consumers in locations $\vartheta(\mathbf{z}, \mathbf{p})$ is ${ }^{9}$

$$
\pi_{i}=L \int_{z \in \vartheta(\mathbf{z}, \mathbf{p})}\left[p_{i}-k_{i}-2 \tau D(z, i)\right] d z .
$$

The function $\vartheta(\mathbf{z}, \mathbf{p})$ 's dependence on $\mathbf{z}$ and $\mathbf{p}$ is described below.

The solution concept employed is that of SPNE: each $z_{i}$ in the support of $\omega_{i}$ is optimal given the strategies of the other players, and each price in the support of $\omega_{i}$ is optimal in each subgame given $\mathbf{z}$ and the strategies of the other players in that subgame. Finally, I restrict attention to equilibria in which no firm randomizes over location.

Market share and profit with no "undercutting."-Given locations, label firms such that firm $i$ s neighbor in the clockwise (counterclockwise) direction is $i+1(i-1)$ for all $i$, where the vector of firms, $\mathbf{n} \equiv(0$, $\ldots, n-1)$, is defined $\bmod (n)$. Similarly, define $\mathbf{p} \equiv\left(p_{0}, \ldots, p_{n-1}\right)$ and $\mathbf{k} \equiv\left(k_{0}, \ldots, k_{n-1}\right)$ as $\bmod (n) .^{10}$

For the moment, consider a price vector $\mathbf{p}$ for which no firm is undercut. A firm is undercut if it supplies no customers. Assuming that no firm is undercut is equivalent to assuming that there exists an indifferent consumer between each pair of neighbors $i$ and $i+1$. Focus on an arbitrary firm $i$ and its two neighbors, firms $i-1$ and $i+1$. I solve for firm $i$ 's market share and profit given prices, $\mathbf{p}$, and the distance between firm $i$ and its two neighbors, $d_{i-1, i}$ and $d_{i, i+1} ; d_{i-1, i}$ is the distance between firms $i-1$ and $i$ and $d_{i, i+1}$ is the distance between firms $i$ and $i+1$. Define $\mathbf{d} \equiv\left(d_{0,1}, \ldots, d_{n-1,0}\right)$ as $\bmod (n) .{ }^{11}$ Manipulating equation (1) yields the distance, $x_{i, i+1}$, between firm $i$ and the consumer indifferent between firms $i$ and $i+1$ :

$$
x_{i, i+1}=\frac{1}{2 t}\left(p_{i+1}-p_{i}+t d_{i, i+1}\right) .
$$

\footnotetext{
${ }^{8}$ The strategies defined above are behavior strategies. However, behavior strategies and mixed strategies are equivalent in this game. For the definition of behavior strategies and the equivalence of behavior strategies and mixed strategies in games of perfect recall, see Fudenberg and Tirole (2000, 83-90).

${ }^{9}$ In eq. (3) I assume both that $\vartheta$ is a measurable set and that if any consumer in location $z$ buys from firm $i$, then all consumers in location $z$ buy from $i$. Each assumption is made without loss of generality.

${ }^{10} \mathrm{~A}$ vector $\mathbf{x}$ is $\bmod (n)$ if $x_{j}=x_{j-n}$ for all $j$.

${ }^{11}$ That the vector $\mathbf{d}$ is $\bmod (n)$ implies that $d_{j, j+1} \equiv d_{j+n, j+n+1}$ for all $j$.
} 
Similarly, the distance, $x_{i, i-1}$, between firm $i$ and the consumer indifferent between firms $i$ and $i-1$ is

$$
x_{i, i-1}=\frac{1}{2 t}\left(p_{i-1}-p_{i}+t d_{i-1, i}\right) .
$$

Firm $i$ 's market share is $x_{i}=x_{i, i-1}+x_{i, i+1}$ :

$$
x_{i}=\frac{1}{2 t}\left[p_{i-1}+p_{i+1}-2 p_{i}+t\left(d_{i-1, i}+d_{i, i+1}\right)\right] .
$$

Firm $i$ 's average cost of supplying consumers between itself and firm $i+1$ is $k_{i}+\tau x_{i, i+1}$. Similarly, the average cost of supplying consumers located between itself and firm $i-1$ is $k_{i}+\tau x_{i, i-1}$. Hence, firm $i$ 's profit is

$$
\pi_{i}=L x_{i}\left(p_{i}-k_{i}\right)-L \tau\left(x_{i, i-1}^{2}+x_{i, i+1}^{2}\right) .
$$

The first term in equation (7) is the standard portion of profit; it is sales multiplied by absolute markup. The second term in equation (7) is firm $i$ 's total cost of shipping; if $\tau=0$, then this term equals zero.

General market share and profit.-Here I drop the assumption that no firm is undercut. More generally, fix an arbitrary $\mathbf{d}$ for which $d_{i, i+1}>0$ for all $i$ and fix an arbitrary p. ${ }^{12}$ Denote by $D_{i+1}(i, j)$ the minimum distance between firms $i$ and $j$ over an arc length on which firm $i+1$ is located: $D_{i+1}(i, j) \equiv \sum_{k=i}^{j-1} d_{k, k+1}$. Similarly, denote by $D_{i-1}(i, j)$ the minimum distance between firms $i$ and $j$ over an arc length on which firm $i-1$ is located: $D_{i-1}(i, j) \equiv \sum_{k=j}^{i-1} d_{k, k+1}$. Let $D(i, j)$ denote the minimum distance between firms $i$ and $j: D(i, j) \equiv \min \left\{D_{i-1}(i, j), D_{i+1}(i, j)\right\}$. There are three possibilities for firm $i$ 's market share. First, if firm $i$ is undercut by another firm, then $x_{i}=0$. This occurs if there exists a firm $j$ such that $p_{j}-p_{i}+t D(i, j)<0$; at these prices every consumer strictly prefers buying from firm $j$ rather than from firm $i$. Second, if firm $i$ undercuts all other firms in the market, then $x_{i}=1$. This occurs if $p_{i}-p_{j}+$ $t D(i, j)<0$ for all $j \neq i$; at these prices each consumer prefers buying from firm $i$ rather than from any other firm. In the final possibility, firm $i$ neither undercuts all firms in the market nor is undercut by any firm in the market. In this case, if firm $j\left(\right.$ firm $j^{\prime}$ ) is firm $i$ 's closest neighbor in the clockwise (counterclockwise) direction such that there exists a consumer indifferent between firm $i$ and firm $j$ (firm $j^{\prime}$ ), then

$$
x_{i}=\frac{1}{2 t}\left\{p_{j}+p_{j^{\prime}}-2 p_{i}+t\left[D(i, j)+D\left(i, j^{\prime}\right)\right]\right\} .
$$

If there exists an indifferent consumer between each pair of neighbors,

${ }^{12}$ The assumption that $d_{i, i+1}>0$ is made only for expositional simplicity. 
then equation (8) is equivalent to equation (6). In this case firm $i$ supplies part of the market, firm $j$ is firm $i+1$, firm $j^{\prime}$ is firm $i-1$, and $D(i, j)+D\left(i, j^{\prime}\right)=d_{i-1, i}+d_{i, i+1}$. In the general case in which market share is given by equation (8), firm $i$ 's profit is given by equation (7), where $x_{i, i+1}\left(x_{i, i-1}\right)$ denotes firm $i$ 's market share on the side on which it is neighbored by firm $i+1(i-1)$.

\section{Equilibrium}

This is a simple two-stage game without a simple solution. In subsection A I demonstrate the well-known result that the game allows no pure strategy SPNE. I also outline my strategy for proving the existence of a set of SPNE in which strategies are pure along the equilibrium path. In subsection B I provide an existence and characterization proposition. Additionally, I sketch the proof and explain the proposition. In subsection C I provide a uniqueness result that holds if $\tau>0$ and sketch its proof. With uniqueness, comparative static results become empirically meaningful. In subsection D I investigate the comparative statics of equilibria that survive the refinement. In subsection E I discuss empirical implementation, focusing on one of the paper's central results.

\section{A. No Pure Strategy SPNE}

D'Aspremont et al. (1979) prove that no pure strategy SPNE exists in a similar game with two symmetric firms locating on a line. The fundamental problem is that profits are not globally quasi-concave. Their result extends to the current game with arbitrarily many heterogeneous firms locating on the circumference of the circle. Figure 2 demonstrates

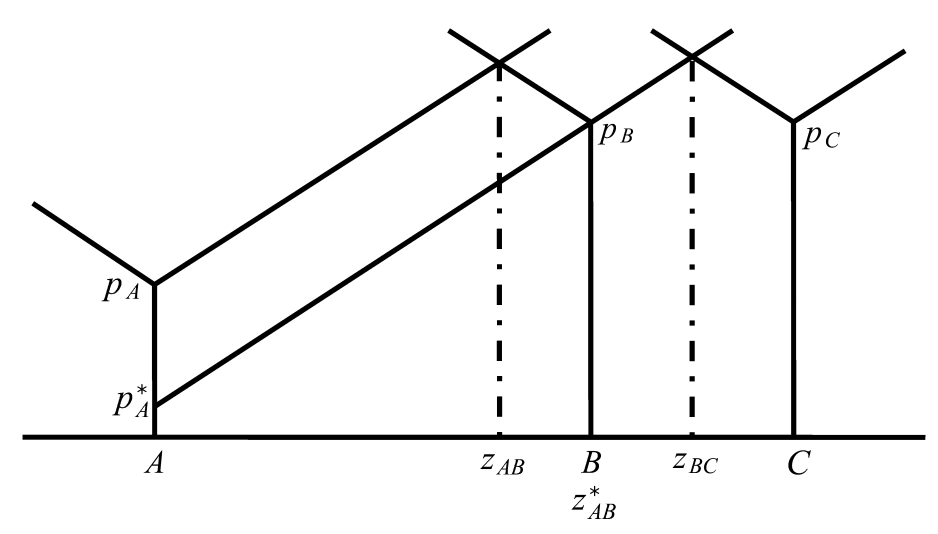

FIG. 2.-Market shares are discontinuous in prices 
that market shares are discontinuous in prices. It depicts the locations of firms $A, B$, and $C$; two prices for firm $A, p_{A}$ and $p_{A}^{*}$; firm $B$ 's price $p_{B}$; and firm $C$ 's price $p_{C}$. If firm $A$ charges price $p_{A}$, consumer $z_{A B}$ is indifferent between buying from firms $A$ and $B$. In a neighborhood around $p_{A}$, firm $A$ 's market share and profit are continuous in its price. However, if firm $A$ charges price $p_{A}^{*}$, consumer $z_{A B}^{*}$, located at the same point as firm $B$, is indifferent between firms $A$ and $B$. At $p_{A}^{*}$, the consumers between firm $B$ and consumer $z_{B C}$ are also indifferent between $A$ and $B$; however, according to the tie-breaking rule, they buy from $B$. For an arbitrarily small reduction in firm $A$ 's price, $A$ gains a discrete mass of customers from $B$ (all customers between firm $B$ and consumer $\left.z_{B C}\right)$. Firm $A$ is said to undercut firm $B$ if $A$ charges a price below $p_{A}^{*}$. This example demonstrates that there are prices at which a firm's market share is discontinuous in its own price; therefore, its profit is discontinuous as well. ${ }^{13}$

Because profit functions are globally neither continuous nor quasiconcave in prices, there exist many price stage subgames for which there is no pure strategy equilibrium in prices. Thus, there is no pure strategy SPNE. According to Reny (1999), there exists a mixed strategy equilibrium to every subgame.

In solving for mixed strategy SPNE, my analysis involves backward induction. Typically, this would necessitate solving for each player's equilibrium probability distribution over prices as a function of locations in every subgame. Unfortunately, this is prohibitively difficult with $n$ heterogeneous firms. In a similar framework, a two-stage game with two symmetric firms locating on a line interval, Osborne and Pitchik (1987) are unable to solve analytically for firm profit in many subgames. They are forced to solve for an SPNE computationally. This problem only becomes more difficult with arbitrarily many asymmetric firms.

My approach is slightly different. I conjecture a set of equilibria in which strategies are pure along the equilibrium path. ${ }^{14}$ I then propose an auxiliary game, defined below, which differs from the real game so as to permit the existence of pure strategy SPNE. I proceed in three steps, each corresponding to a lemma. First, I prove that if all firms follow conjectured equilibrium strategies, then profits are equal in the real and auxiliary games. Second, using backward induction, I prove that there are no profitable, unilateral deviations in the auxiliary game. Finally, I prove either that profit in the auxiliary game is an upper bound for profit in the real game or that a unilateral deviation in the real game strictly reduces a firm's profit. Combining these three steps gives

${ }^{13}$ This lack of continuity (and lack of quasi concavity) is not an artifact of the specific tie-breaking rule.

${ }^{14}$ When firms locate on a line interval, as in Osborne and Pitchik (1987), there is no equilibrium in which strategies are pure along the equilibrium path. 


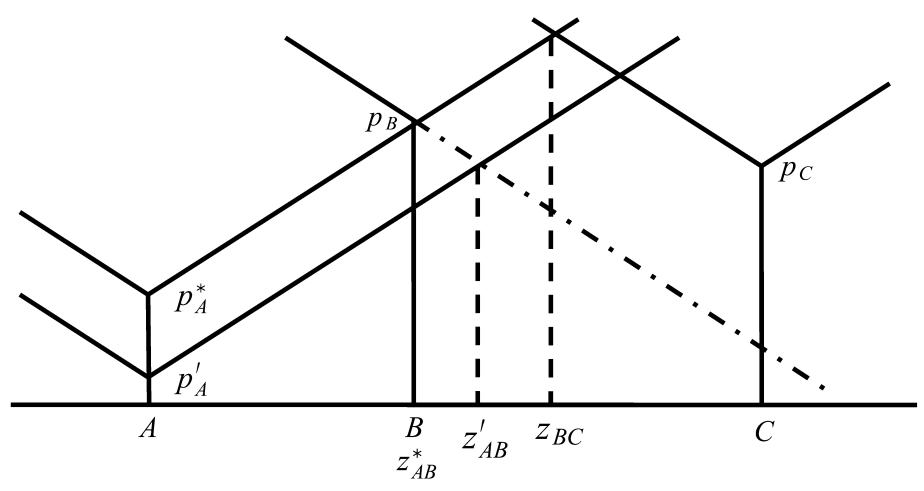

FIG. 3.-Market shares in the auxiliary and real games

the desired result: the conjectured equilibrium is an SPNE in the real game. The key insight is that once I am able to bound expected profit in the real game with profit in the auxiliary game, I avoid the necessity of solving for a mixed strategy equilibrium in an arbitrary subgame. Toward achieving this goal, I define the auxiliary game.

Definition 1. The auxiliary game is identical to the real game except that each firm's market share is given by equation (6) in the auxiliary game instead of equation (8) in the real game.

Demand systems differ in the auxiliary game and the real game. A firm's market share is given by equation (6) in the auxiliary game whereas it is given either by zero, by one, or by equation (8) in the real game. Market shares in the real and auxiliary games are identical for all firms only in the special case in which there is an indifferent consumer located between each pair of neighbors. In the real game, firm $i$ s market share is given by equation (6) only if $x_{i, i-1} \geq 0$ and $x_{i, i+1} \geq 0$; otherwise, $x_{i}=0$ if either $x_{i, i-1}<0$ or $x_{i, i+1}<0$, even if $x_{i, i-1}+x_{i, i+1}>0$. Figure 3 demonstrates the difference between how market shares are determined in the auxiliary and real games. In the real game, if firm $A$ were to decrease its price from $p_{A}^{*}$ to $p_{A}^{\prime}$, $A$ would undercut $B$. Firm $B$ 's market share would equal zero because $x_{B, A}<0$, even though $x_{B, A}+x_{B, C}>0$. However, if $A$ were to decrease its price from $p_{A}^{*}$ to $p_{A}^{\prime}$ in the auxiliary game, then the new consumer indifferent between $A$ and $B$ would be located at point $z_{A B}^{\prime}$. All consumers to the left of $z_{A B}^{\prime}$ buy from $A$ rather than from $B$; consumers between $z_{A B}^{\prime}$ and $z_{B C}$ continue buying from $B$. This demonstrates that market shares are continuous in the auxiliary game. Moreover, profit is quasi-concave in the auxiliary game. Hence, in every price stage subgame there exists a pure strategy equilibrium in the auxiliary game. 


\section{B. Existence and Characterization}

The following proposition states that there exists a set of equilibria to the real game. It also characterizes economic outcomes for any equilibrium in this set of equilibria. The proposition holds regardless of whether shipping costs are zero, $\tau=0$, or positive, $\tau>0$.

Proposition 1. For any set of parameters $\theta \equiv(n, t, \tau, L)$ and $k \geq$ 0 there exists a $\phi(\theta, k)>0$ such that if $k_{i} \in[k, k+\phi(\theta, k)]$ for all $i$, then there is a nonempty set $O^{*} \in \Omega^{n}$ such that any $\omega \in O^{*}$ is an SPNE. The set $O^{*}$ has the following properties:

1. Strategies are pure along the equilibrium path for all $\omega \in O^{*}$.

2. For any order of the firms around the circle there exists a corresponding $\omega \in O^{*}$.

3. The distance between each pair of neighbors, firms $i$ and $i+1$, is

$$
d_{i, i+1}^{*}=\frac{1}{n}+\frac{2}{3 t+2 \tau}\left(\bar{k}-\frac{k_{i}+k_{i+1}}{2}\right)
$$

and firm $i$ s price, market share, and profit are

$$
\begin{aligned}
p_{i}^{*} & =(t+\tau)\left(\frac{1}{n}+\frac{2}{3 t+2 \tau} \bar{k}\right)+\frac{t}{3 t+2 \tau} k_{i}, \\
x_{i}^{*} & =\frac{1}{n}+\frac{2}{3 t+2 \tau}\left(\bar{k}-k_{i}\right), \\
\pi_{i}^{*} & =L t\left(x_{i}^{*}\right)^{2} .
\end{aligned}
$$

Proof. Let $\pi_{i}^{A *}\left(\pi_{i}^{*}\right)$ denote firm $i$ 's profit in the auxiliary game (real game) if $\boldsymbol{\omega} \in O^{*}$. Let $\boldsymbol{\pi}_{i}^{A \prime}\left(E\left[\pi_{i}^{\prime}\right]\right)$ denote firm $i$ 's profit in the auxiliary game (expected profit in the real game) if it unilaterally deviates from $\omega \in O^{*}$ along the equilibrium path. In Appendix A I prove the following three lemmas.

Lemma 1. Let $\phi_{1}(\theta, k) \equiv(3 t+2 \tau) /[2(n-1)]>0$. If $k_{i} \in[k, k+$ $\left.\phi_{1}(\theta, k)\right]$ for all $i$, then $\pi_{i}^{A *}=\pi_{i}^{*}$ for all $i$.

Lemma 2. There exists a $\phi_{2}(\theta, k)>0$ such that if $k_{i} \in\left[k, k+\phi_{2}(\theta\right.$, $k)$ ] for all $i$, then $\pi_{i}^{A *} \geq \pi_{i}^{A \prime}$ for all $i$ if $\tau \geq 0$ and $\pi_{i}^{A *}>\pi_{i}^{A \prime}$ for all $i$ if $\tau>0$.

Lemma 3. There exists a $\phi_{3}(\theta, k)>0$ such that if $k_{i} \in\left[k, k+\phi_{3}(\theta\right.$, $k)]$ for all $i$, then either $\pi_{i}^{A \prime} \geq E\left[\pi_{i}^{\prime}\right]$ for all $i$ or $\pi_{i}^{*}>E\left[\pi_{i}^{\prime}\right]$ for all $i$.

Let $\phi(\theta, k) \equiv \min _{j} \phi_{j}(\theta, k)$. Suppose that $k_{i} \in[k, k+\phi(\theta, k)]$ for all $i$. Combining lemmas 1,2 , and 3 yields either the relationship $\pi_{i}^{*}=$

$\pi_{i}^{A *} \geq \pi_{i}^{A \prime} \geq E\left[\pi_{i}^{\prime}\right]$ or the relationship $\pi_{i}^{*}>E\left[\pi_{i}^{\prime}\right]$. Both of these relationships yield the desired result that $\pi_{i}^{*} \geq E\left[\pi_{i}^{\prime}\right]$. Thus, any $\omega \in O^{*}$ is an SPNE. QED 
1. Intuition for the Proof

Before describing proposition 1, I provide the basic intuition for lemmas 1,2 , and 3 .

Lemma 1.-According to lemma 1, if firms are sufficiently similar and $\omega \in O^{*}$, then profit in the auxiliary game equals profit in the real game. If $\omega \in O^{*}$, then firms use pure strategies on the equilibrium path; and if $\omega \in O^{*}$ and $k_{i} \in\left[k, k+\phi_{1}(\theta, k)\right]$, then no firm overtakes another in the real game because $k_{i} \in\left[k, k+\phi_{1}(\theta, k)\right]$ for all $i$ is a sufficient condition under which $x_{i}^{*} \geq 0$ for all $i$. When all firms use pure strategies and no firm overtakes another, each firm's profit is the same in the real game as it is in the auxiliary game.

Lemma 2.-According to lemma 2, there is no profitable deviation for firm $i$ in the auxiliary game. The case with two symmetric firms on the unit circumference and $\tau=0$ has been considered by Kats (1995). He shows that for a fixed location for firm $A$, firm $B$ 's profit is constant for any location that is a distance of no less than $\frac{1}{4}$ from firm $A .{ }^{15}$ In what follows I provide the intuition for why firm $i$ does not benefit, in the auxiliary game, from making a small deviation in location.

Given locations, firm's $i$ 's best-response function in the auxiliary game is

$$
\frac{2(\tau+2 t)}{t+\tau} p_{i}=p_{i-1}+p_{i+1}+t\left(d_{i-1, i}+d_{i, i+1}\right)+\frac{2 t}{t+\tau} k_{i}
$$

This gives a system of $n$ first-order conditions

$$
A \mathbf{p}^{\prime}=\mathbf{b}^{\prime}
$$

where

$$
A \equiv\left[\begin{array}{ccccc}
\frac{2(2 t+\tau)}{t+\tau} & -1 & 0 & 0 & -1 \\
-1 & \frac{2(2 t+\tau)}{t+\tau} & -1 & 0 & 0 \\
\ldots & \cdots & \ldots & \ldots & \cdots \\
-1 & 0 & 0 & -1 & \frac{2(2 t+\tau)}{t+\tau}
\end{array}\right]
$$

${ }^{15}$ In this respect, the result in Kats (1995) is very similar to a point made in d'Aspremont et al. (1979). With two firms, the circle is similar to the unit interval with the added restriction that firms must locate symmetrically. Under this restriction, d'Aspremont et al. demonstrate that there exists a pure strategy price stage equilibrium as long as the distance between the two firms is no less than $\frac{1}{4}$. 
with

$$
\begin{aligned}
& \mathbf{b} \equiv\left(b_{0}, \ldots, b_{n-1}\right) \bmod (n), \\
& b_{i} \equiv t\left(d_{i-1, i}+d_{i, i+1}\right)+\frac{2 t}{t+\tau} k_{i} .
\end{aligned}
$$

As I prove in Appendix A, the solution to this system has the form

$$
\begin{aligned}
p_{i}= & \beta_{1}\left(d_{i-1, i}+d_{i, i+1}\right)+\beta_{2}\left(d_{i-2, i-1}+d_{i+1, i+2}\right)+\cdots \\
& +\delta_{0} k_{i}+\delta_{1}\left(k_{i-1}+k_{i+1}\right)+\cdots \quad \text { for all } i .
\end{aligned}
$$

Firm $i$ 's profit and market share in the auxiliary game are

$$
\begin{aligned}
& \pi_{i}=L x_{i}\left(p_{i}-k_{i}\right)-L \tau\left(x_{i, i-1}^{2}+x_{i, i+1}^{2}\right), \\
& x_{i}=\frac{1}{2 t}\left[p_{i-1}+p_{i+1}-2 p_{i}+t\left(d_{i-1, i}+d_{i, i+1}\right)\right] .
\end{aligned}
$$

Suppose that all firms $j \neq i$ locate as in $\omega \in O^{*}$ and let firm $i$ make an arbitrary $\varepsilon \in\left(0, d_{i, i+1}^{*}\right)$ deviation, in the direction of firm $i+1$, from the location prescribed by $\omega$. In Appendix A I prove that this deviation strictly decreases $\pi_{i}$ if $\tau>0$ and does not affect $\pi_{i}$ if $\tau=0$. I sketch the proof here. The unilateral deviation does not affect the standard part of profit, $L x_{i}\left(p_{i}-k_{i}\right)$, regardless of whether $\tau=0$ or $\tau>0$. The reason is that $p_{i}$ and $x_{i}$ are unaffected by the deviation. That $p_{i}$ is unaffected is clear from equation (12). Firm $i$ 's market share is unaffected because, although the prices of its two direct competitors change, the linear cost of transportation implies that the sum of these prices remains unchanged. That is, firm $i+1$ 's price decreases the exact amount, $\varepsilon\left(\beta_{1}-\beta_{2}\right)$, that firm $i-1$ 's price increases, $\varepsilon\left(\beta_{1}-\beta_{2}\right)$. Given that $x_{i}$ $\left(\equiv x_{i, i-1}+x_{i, i+1}\right)$ is unchanged by firm $i$ s deviation, firm $i$ 's shipping cost, $\tau\left(x_{i, i-1}^{2}+x_{i, i+1}^{2}\right)$, is minimized by locating such that $x_{i, i-1}=x_{i, i+1} \cdot{ }^{16}$ Hence, firm $i$ s profit in the auxiliary game is maximized by choosing to locate such that in the equilibrium to the second stage it is located in the center of its market share. This is the location prescribed by $\omega \in O^{*}$.

Lemma 3.-According to lemma 3, either $\pi_{i}^{*}>E\left[\pi_{i}^{\prime}\right]$ or $\pi_{i}^{A \prime} \geq E\left[\pi_{i}^{\prime}\right]$. Here I focus on explaining the result that expected profit in the real game is bounded above by profit in the auxiliary game when no firm is undercut with probability one. ${ }^{17}$ This is clearly true if firms locate such that a pure strategy equilibrium exists to the price stage. Suppose

${ }^{16}$ The problem is $\min _{a, b}\left\{a^{2}+b^{2}\right\}$ subject to $a+b=c$. The solution is $a=b=c / 2$.

${ }^{17}$ If any firm is undercut with probability one, then $\pi_{i}^{*}>E\left[\pi_{i}^{\prime}\right]$ is the relevant relationship. 
that firms locate such that there exists no pure strategy equilibrium in the subgame. Denote the equilibrium vector of prices in the auxiliary game by $\mathbf{a} \equiv\left(a_{0}, \ldots, a_{n-1}\right)$. Denote the supremum of the support over which firm $i$ randomizes its price with positive probability in the real game by $M_{i}$. In Appendix A I prove that $M_{i} \leq a_{i}$ for all $i$.

Intuitively, the auxiliary game reduces the incentive for firms to decrease their prices by decreasing competition. Thus, the auxiliary game increases firms' expected profits. To highlight this intuition, compare the costs and benefits to reducing firm $i$ 's price in the real and the auxiliary games. Fix the locations of the $n$ firms such that if all firms charge prices given in equation (12), then no firm is undercut. In both the real and auxiliary games, the marginal cost to firm $i$ of reducing its price to gain new consumers is the change in price times the mass of its inframarginal consumers. The difference between the real and auxiliary games is that firm $i$ s marginal benefit to reducing its price from $p_{i+1}-t d_{i, i+1}$ (or from $p_{i-1}-t d_{i-1, i}$ ) is strictly greater in the real game than in the auxiliary game. In the real game, if firm $i$ reduces its price from $p_{i+1}-t d_{i, i+1}$ by an arbitrarily small amount, it undercuts its neighbor $i+1$; the marginal benefit to $i$ of undercutting $i+1$ equals the discrete mass of consumers it gains by undercutting $i+1$ times the limit price required to undercut $i+1$. However, firm $i$ is unable to gain a discrete mass of consumers by reducing its price by an arbitrarily small amount in the auxiliary game.

The fact that firms have an incentive to undercut each other in the real game that is not present in the auxiliary game conveys the central point: the auxiliary game reduces competition. Reduced competition and the fact that prices are strategic complements imply that profit in the auxiliary game is greater than expected profit in the real game.

\section{Explaining Proposition 1}

Before I proceed to provide a uniqueness result and carry out comparative static exercises, it is important to explain proposition 1 in more depth. In particular, there are four general issues to clarify before considering the implications of the results. The first three issues concern the results in parts 1, 2, and 3 of the proposition. The fourth concerns the condition that firms have sufficiently similar marginal costs.

Mixed strategies.-The assumption that firms randomize over prices may seem unrealistic. ${ }^{18}$ However, although all SPNE to the game are necessarily mixed strategy equilibria, according to part 1 of proposition 1 , strategies are pure along the equilibrium path for all $\omega \in O^{*}$. Firms randomize over prices only off the equilibrium path.

\footnotetext{
${ }^{18}$ Frequent sales may be evidence of randomization (see, e.g., Pesendorfer 2002).
} 

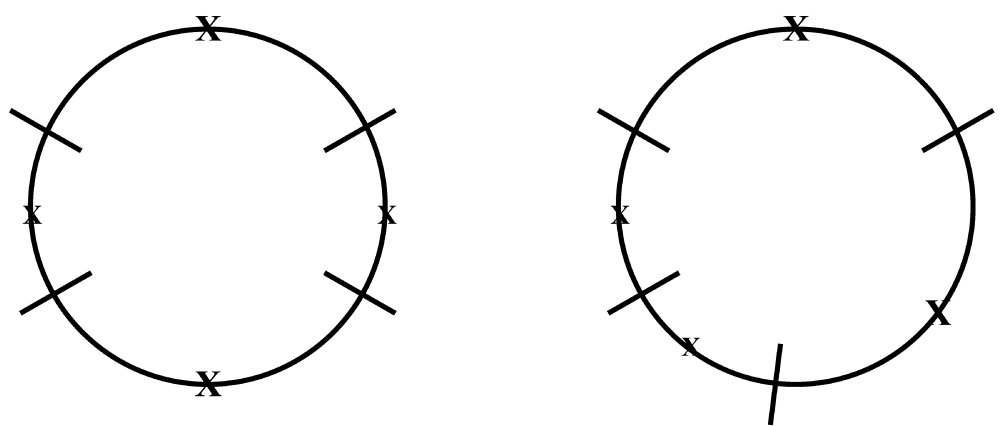

Fig. 4.-Two equilibrium orders are depicted. On the left, the low-cost firms (large X's) are separated by the high-cost firms (small x's). On the right, the low-cost firms neighbor each other. The figure includes graphical representations of market shares.

Multiple orders, multiple equilibria.-According to part 2 of proposition 1 , for any order of the firms around the circle there exists a corresponding $\omega \in O^{*}$. The following simple example demonstrates the existence of multiple equilibria in $O^{*}$.

Suppose that there are four firms. Two of these firms have equally low marginal costs and two have equally high marginal costs. In this simple example, there are two possible arrangements of the firms around the circle. In one, the two low-cost firms neighbor one another. In the other, the low-cost firms are separated by the high-cost firms. Each of these arrangements corresponds to an equilibrium in the set $O^{*}$. The two possible orders are shown in figure 4. Not only do both of these orders correspond to an equilibrium, but a given firm's price, market share, and profit are identical across the equilibria corresponding to the two orders. As I describe below, in order for each firm's price, market share, and profit to be the same in each equilibrium, it must be that the distance between neighbors is strictly decreasing in the cost of each neighbor. This is evident in figure 4 .

Outcome equivalence of equilibria.-As noted above, there are multiple equilibria in $O^{*}$. Nevertheless, according to part 3 of proposition 1, with the exception of location, all economically relevant outcomes-price, market share, and profit—are identical across all equilibria in $O^{*}$. These outcomes depend on another producer's marginal cost only through its impact on the average marginal cost, $\bar{k}$. This result might seem surprising given that the price stage is characterized by localized competition. In the price stage, two firms are direct competitors only if they neighbor each other in product space; and in most subgames a firm's profit is clearly affected more by its neighbors' marginal costs than by those of other firms in the market. In what follows I explain the economic intuition yielding the result. 


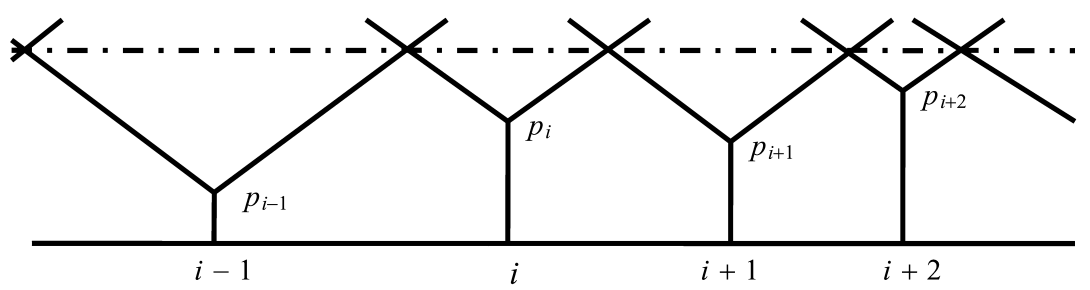

FIG. 5.-All indifferent consumers face identical location-adjusted prices in all $\omega \in O^{*}$

When $\bar{k}$ and the distances between firms are held fixed, a firm's profit is greater the higher the marginal costs of its neighbors. This fact seems to be at odds with the result that in all $\omega \in O^{*}$ a firm earns the same profit regardless of the marginal costs of its two neighbors (given $\bar{k}$ ). A second piece of intuition reconciles these two results: a firm's profit increases in its isolation $\left(d_{i-1, i}+d_{i, i+1}\right)$. This suggests that in order for a firm's profit to depend on its neighbors' marginal costs only through the impact of these marginal costs on $\bar{k}$, it must be that firms are compensated through isolation for the marginal costs of their neighbors. That is, more productive firms are more isolated than less productive firms, all else equal. This is precisely what equation (9) entails.

The above intuition implies that if a firm's profit depends on its neighbors' marginal costs only through $\bar{k}$, then firms must be compensated through isolation for the marginal costs of their neighbors. However, the above intuition does not clarify why a firm's profit depends on its neighbors' marginal costs only through $\bar{k}$ in all $\omega \in O^{*}$. A special feature of all $\omega \in O^{*}$ is that each firm locates at the center of its market share in order to minimize the cost of shipping: that is, $x_{i, i-1}=x_{i, i+1}$ for all $i$. If firm $i$ is centered in its market share, the consumers on either edge of $i$ 's market share face the same location-adjusted prices: $x_{i, i-1}=x_{i, i+1}$ implies $p_{i}+t x_{i, i-1}=p_{i}+t x_{i, i+1}$. This is true of each firm in all $\omega \in O^{*}$, implying that all indifferent consumers face identical location-adjusted prices (see fig. 5). If all firms are centered in their market shares and all firms price optimally, then firm $i$ 's profit, market share, and price will depend on only its own marginal cost and the location-adjusted price faced by all indifferent consumers. Thus, each firm's profit depends on its neighbors' marginal costs only through the impact of these marginal costs on $\bar{k}$, which in turn helps determine the location-adjusted price that all indifferent consumers face.

Permissible asymmetries.-Although proposition 1 encompasses the case in which firms are symmetric as well as the case in which they are asymmetric, the results are proved only in a neighborhood of symmetry. All firms must have sufficiently similar marginal costs. A necessary condition for the existence of each equilibrium $\omega \in O^{*}$ is $k_{i} \in[k, k+$ 
$\phi(\theta, k)]$ for all $i$. The degree of permissible asymmetry, $\phi(\theta, k)$, depends on the parameters of the model.

Unfortunately, it is extremely difficult to fully characterize $\phi(\theta, k)$ because I use a perturbation argument. I prove that if firms are symmetric, then no firm is ever undercut with probability one in any SPNE. I then argue that if firms are sufficiently similar, then this result continues to hold if firms are asymmetric.

In this subsection I discuss how $\phi(\theta, k)$ varies with the parameters of the model in two ways. First, I consider comparative statics on $\phi_{1}(\theta, k)$, where $\phi_{1}(\theta, k)$ is an upper bound on $\phi(\theta, k)$ that is defined in lemma 1. Second, I explicitly solve for $\phi(\theta, k)$ in two examples-one with $n=2$ and one with $n=3$-to illustrate how $\phi(\theta, k)$ varies with $n$.

In lemma 1 I prove that if $k_{i} \in\left[k, k+\phi_{1}(\theta, k)\right]$ for all $i$, where $\phi_{1}(\theta$, $k) \equiv(3 t+2 \tau) /[2(n-1)]$, then $x_{i}^{*} \geq 0$ if $\omega \in O *{ }^{19}$ Recall that

$$
x_{i}^{*}=\frac{1}{n}+\frac{2}{3 t+2 \tau}\left(\bar{k}-k_{i}\right) .
$$

Moreover, in proposition 1 I define $\phi(\theta, k)$ such that $\phi_{1}(\theta, k)$ is its upper bound: $\phi(\theta, k) \leq \phi_{1}(\theta, k)$. The permissible asymmetry $\phi_{1}$ is strictly increasing in both transportation costs, $t$ and $\tau$; is strictly decreasing in the number of firms in the market, $n$; and is independent of $k$ and $L$. These comparative statics are intuitive. They all follow from the fact that $x_{i}^{*} \geq 0$ if and only if $k_{i}-\bar{k} \leq(3 t+2 \tau) / 2 n$.

First, consider demand density $L$. Both $\phi$ and $\phi_{1}$ are independent of $L$ because there are constant returns to scale. Second, consider the minimum cost level $k$. The condition under which firm $i$ 's market share is positive depends on the absolute difference between $k_{i}$ and $\bar{k}$. Hence, a change in $k$ does not affect $\phi_{1}$. Third, consider the number of firms $n$. As $n$ increases, firms become less isolated and, all else equal, firm $i$ 's market share decreases. Next, consider the shopping cost $t$. As $t$ increases, differences in marginal costs become less important to consumers, who must bear increasingly large shopping costs. Thus, as $t$ increases, the market shares of the least productive firms increase, implying that $\phi_{1}(\theta, k)$ increases. Finally, the intuition for the impact of $\tau$ on $\phi_{1}(\theta, k)$ is identical to that of the impact of $t$ on $\phi_{1}(\theta, k)$.

Although comparative statics on $\phi_{1}(\theta, k)$ help provide intuition, it is important to note that $\phi(\theta, k)$ may always be strictly less than $\phi_{1}(\theta, k)$; $\phi(\theta, k)$ may be bounded above by some $\phi_{j}(\theta, k)<\phi_{1}(\theta, k)$. To understand how $\phi$ varies with $n$, consider two examples in which $\tau=0$ and $t=1$.

\footnotetext{
${ }^{19}$ The result that $x_{i}^{*} \geq 0$ is stronger than the statement that firm $i$ has a nonnegative market share, which is true by definition. According to its definition, $x_{i}^{*}$ can be negative. However, $x_{i}^{*}$ corresponds to firm $i$ 's market only if $x_{j}^{*} \geq 0$ for all $j$.
} 
In the first example there are two firms. In the second example there are three firms. For each example I solve for $\phi$.

Example 1. Suppose that there are two firms, $A$ and $B$, with $k_{A}<$ $k_{B}$. In this case $\omega \in O^{*}$ is an SPNE if

$$
k_{B} \leq 3\left(1-\frac{1}{2} \sqrt{3}\right)+k_{A} \cong 0.4012+k_{A} .
$$

If this condition is violated, then given firm $B$ 's location, firm $A$ would always have an incentive to locate directly on top of firm $B$ and limit price at firm $B$ 's marginal cost. At this price, firm $A$ supplies the entire market.

Example 2. Suppose that there are three firms, $A, B$, and $C$, with $k_{A}<k_{B}=k_{C}$. In this case $\omega \in O^{*}$ is an SPNE if

$$
k_{B} \leq \frac{147}{128}-\frac{27}{128} \sqrt{17}+k_{A} \cong 0.2787+k_{A} .
$$

If this condition is violated and firms $B$ and $C$ locate as prescribed by $\omega$, then firm $A$ would have an incentive to locate at the midpoint of the shorter arc length between $B$ and $C$ (the arc of length $d_{B, C}$ rather than the arc of length $d_{A, B}+d_{C, A}$ ). In this location, firm $A$ would limit price at $k_{B}-\frac{1}{2} d_{B, C}$. At this price, firm $A$ supplies the entire market.

\section{Uniqueness}

As shown above, there may be multiple equilibria in the set $O^{*}$. In fact, if $\tau=0$, it is easy to apply the proof of proposition 1 to show that there exist other equilibria $\omega^{\prime} \notin O^{*}$ that are pure along the equilibrium path. As an example, suppose that $\tau=0$ and that all firms $j \neq i$ locate as in $\omega \in O^{*}$. Let firm $i$ make an $\varepsilon \in\left(0, d_{i, i+1}^{*}\right)$ deviation, in the direction of firm $i+1$, from the location prescribed by $\omega$. As I prove in Appendix A and discuss above, according to lemma 2, firm $i$ 's profit is $\pi_{i}^{\prime}=\pi_{i}^{*}$ after such a deviation if $\varepsilon$ is sufficiently small that a pure strategy equilibrium exists in the price stage. Moreover, the resulting vector of locations $\mathbf{z}^{\prime}=\left(z_{0}, \ldots, z_{i}^{\prime}, \ldots, z_{n-1}\right)$ corresponds to an equilibrium; according to lemma 2 there is no location $z_{j}^{\prime}$ for any firm $j$ at which firm $j$ 's profit is greater than it would have been at $z_{j}$. Hence, if $\tau=0$, there may exist a continuum of SPNE $\omega^{\prime} \notin O^{*}$ in which firms use pure strategies along the equilibrium path.

If $\tau>0$, then $O^{*}$ is the unique set of SPNE that are pure along the equilibrium path. Recall that a firm incurs a shipping cost of $2 \tau D(z$, i) to "ship" a good to a consumer located at a point $z$, where $\tau \in[0$, t). It is important that firms cannot price-discriminate even if $\tau>0$ : a firm must charge a common price $p_{i}$ to all consumers. The assumption that firms pay a variable shipping cost is straightforward when the model 
is applied to homogeneous good firms that differentiate themselves through geographic locations: consumers and firms share the cost of transporting the good with an exogenous division of transportation costs. When the model is applied to differentiated good firms, the shipping cost can be interpreted as a cost of customer service. A consumer who purchases a good that is farther from her ideal variety may be more likely to require service. The firm must not be able to pass along to the consumer the full cost of service (this could be the outcome of a signaling game in which firms offer warranties) or judge how far the good is from a consumer's ideal before determining the price. I emphasize that the shipping cost is used only to select among equilibria, and for this purpose, it can be arbitrarily small.

Definition 2. An SPNE is strict if any unilateral deviation along the equilibrium path by firm $i$ strictly decreases firm $i$ 's profit.

This is not the standard definition of strict. A more accurate term would be "strict along the equilibrium path."

Proposition 2. If $\tau>0$ and $k_{i} \in[k, k+\phi(\theta, k)]$ for all $i$, then $\omega$ is a strict SPNE if and only if $\omega \in O^{*}{ }^{20}$

According to proposition 2, if $\tau>0$, then all economically relevant outcomes-price, market share, and profit-other than isolation are identical across all strict SPNE. Even with symmetric firms, this is a stronger result than found in either Lancaster (1979) or Economides (1989). Lancaster and Economides prove that there exists an equilibrium in which symmetric firms are symmetrically spaced. They do not obtain uniqueness results.

The proof that $\omega$ is strict if $\omega \in O^{*}$ is straightforward given lemmas 1,2 , and 3. If $\tau>0$, then these lemmas yield either the relationship $\pi_{i}^{*}=\pi_{i}^{A *}>\pi_{i}^{A \prime} \geq E\left[\pi_{i}^{\prime}\right]$ or the relationship $\pi_{i}^{*}>E\left[\pi_{i}^{\prime}\right]$. Each of these implies the result that firm $i$ 's equilibrium profit is strictly greater than its expected profit after it unilaterally deviates from $\omega \in O^{*}$, that is, $\pi_{i}^{*}>E\left[\pi_{i}^{\prime}\right]$. Thus, any $\omega \in O^{*}$ is a strict SPNE. Intuitively, if $\tau>0$, then a firm minimizes its cost of shipping by locating in the middle of its market share; and this is the location prescribed by equation (9).

The statement that $\omega$ is a strict SPNE only if $\omega \in O^{*}$ is proved in three steps. In the first I prove that if a pure strategy equilibrium exists in a price stage subgame, then this is the unique mixed strategy equilibrium. In the second, I prove that if locations are such that a strict equilibrium exists and an arbitrary firm is moved an arbitrarily small distance from its location, then a strict equilibrium in prices still exists. Suppose that $\omega$ is a strict SPNE and suppose that firm $i$ unilaterally deviates from $\omega$ in the location stage but locates within a distance $\varepsilon$ of the location A.

${ }^{20}$ The proofs of proposition 2 and of all subsequent propositions are relegated to App. 
prescribed by $\omega$. Then according to the two results above, there exists an $\varepsilon>0$ such that in the resulting price stage subgame the unique mixed strategy equilibrium is a pure strategy equilibrium.

Using this result, in the third step I prove that each firm must be centered in its market share in every strict SPNE. If firms choose prices optimally and each firm is centered in its market share, then the distance between any two neighbors must be given by equation (9). If firm locations satisfy equation (9), then there is a unique equilibrium in the pricing subgame. In this equilibrium firms choose prices according to equation (10). Thus, all strict SPNE are elements of $O^{*}$.

\section{Comparative Statics}

Isolation.-How do firms' choices of locations given in equation (9) differ from those predicted by Lancaster (1979) and Economides (1989) or assumed by Salop (1979) and Syverson (2004)? In the aforementioned models, each pair of neighbors is separated by a distance of $1 / n$. Recall equation (9):

$$
d_{i, i+1}=\frac{1}{n}+\frac{2}{3 t+2 \tau}\left(\bar{k}-\frac{k_{i}+k_{i+1}}{2}\right) .
$$

The above equation implies that if the average marginal cost of two neighbors equals the average marginal cost of all firms in the market, then the neighbors' varieties are separated by $1 / n$.

Generally, two neighbors, firms $i$ and $i+1$, produce varieties that are separated by more than $1 / n$ if and only if their average cost is less than the average cost of all firms in the market. The distance between neighbors is a strictly decreasing function of their average marginal cost: more productive firms are more isolated, all else equal. Proposition 1 explains that relative isolation is a function of relative productivity. Intuitively, high-cost firms shy away from the harsh competition of low-cost firms. This intuition is an equilibrium argument, however, only if $\tau>0$.

Neighbors are more isolated if there are fewer firms in the market or if the average marginal cost of all firms in the market is greater. With the average marginal cost of all firms held fixed, if there are fewer firms in the market, then all neighbors become more isolated. This is relatively intuitive and in the case with identical firms is standard in Salop (1979) (where it is assumed) and in Lancaster (1979) and Economides (1989) (where it is an equilibrium outcome). The impact of $\bar{k}$ on isolation is more interesting. With the number of firms in the market and the marginal costs of $i$ and $i+1$ held fixed, if the average marginal cost of the other firms in the market increases, then the distance between firms $i$ and $i+1$ increases. Intuitively, if the marginal cost of an arbitrary firm 
$j \neq i, i+1$ increases, $j$ becomes less isolated. In order for $j$ to become less isolated while all firms remain centered in their market shares, the distance between all neighbors $i$ and $i+1$ (where $j \neq i, i+1$ ) must increase.

Transportation costs also have interesting and intuitive impacts on isolation. As either transportation cost increases, firm locations approach the symmetric case considered in Salop (1979) even if firms are asymmetric. As $t$ increases, differences in marginal costs become less important to consumers, who must bear increasingly large shopping costs. In order for all indifferent consumers to face equal locationadjusted prices, isolation must become less responsive to cost differences as $t$ increases. Similar intuition holds for the impact of $\tau$ on isolation.

Price.-Firm $i$ charges the price

$$
p_{i}=(t+\tau)\left(\frac{1}{n}+\frac{2}{3 t+2 \tau} \bar{k}\right)+\frac{t}{3 t+2 \tau} k_{i} .
$$

In the case in which $\tau=0$ and firms are homogeneous $\left(k_{i}=k\right.$ for all $i)$, this pricing equation reduces to that of Salop (1979) in his "competitive equilibrium" case: $p_{i}=(t / n)+k$. In the general case in which firms are heterogeneous, firms with lower costs charge relatively lower prices. However, low-cost firms do not pass along to consumers the entire benefit of their productivity. Absolute markups are strictly decreasing in $k_{i}$ : firms with lower costs set higher absolute markups. ${ }^{21}$

The existence of the new margin of adjustment introduced in this paper, that of isolation, suggests that models that abstract from the isolation margin of adjustment overestimate own-price sensitivity to cost changes. Consider a set of $n \geq 3$ firms located as prescribed by $\omega \in$ $O^{*}$. Suppose that firm $i$ 's marginal cost decreases. If we hold the firms' locations fixed, then firm $i$ 's price reduces to some $p_{i}^{\prime}$. If instead we let the firms adjust their locations such that they are in new equilibrium locations given the new vector of marginal costs, firm $i$ 's price reduces to some $p_{i}^{\prime \prime}$. It is straightforward to prove that $p_{i}^{\prime}<p_{i}^{\prime \prime}$. When firms adjust their locations in response to the lower cost of firm $i$, they leave firm $i$ more isolated. Increased isolation increases firm $i$ 's market power, mitigating $i$ s incentive to reduce its own price.

Market share and profit.-Recall that

$$
\begin{aligned}
& x_{i}=\frac{1}{n}+\frac{2}{3 t+2 \tau}\left(\bar{k}-k_{i}\right), \\
& \pi_{i}=L t\left(x_{i}\right)^{2} .
\end{aligned}
$$

A firm's market share and profit are greater than average if and only

${ }^{21}$ This result is also obtained, e.g., in Melitz and Ottaviano (2005). 
if its cost is less than average. There are two forces supporting this relationship with respect to market share. The standard mechanism is that low-cost firms charge lower prices. Additionally, there is a novel mechanism at work: all else equal, firms with lower costs are more isolated. Low-cost firms earn high profits for two standard reasons: they have larger market shares and they set higher absolute markups.

As $t$ increases, the reward (penalty) to having a low (high) marginal cost decreases. Although a firm's market share and profit are greater than average if and only if $k_{i}<\bar{k}$, the sensitivity of market share and profit to $\bar{k}-k_{i}$ is decreasing in $t$. Indeed, as $t$ converges to infinity, market shares and profits approach those in the symmetric case considered in Salop (1979). Changes in $\tau$ affect market shares and profits similarly.

In summary, we have the following corollary.

Corollary 1 . Suppose that $\omega \in O^{*}$.

1. The term $d_{i, i+1}>1 / n$ if and only if $k_{i}+k_{i+1}<2 \bar{k}$. Moreover, $d_{i, i+1}$ is strictly decreasing in $\left(k_{i}+k_{i+1}\right) / 2$.

2. As either transport cost increases, the distance between two neighbors $i$ and $i+1$ with $k_{i}+k_{i+1}<2 \bar{k}\left(k_{i}+k_{i+1}>2 \bar{k}\right)$ decreases (increases), all else equal.

3. Firm $i$ 's market share, absolute markup, and profit are greater than the market average if and only if $k_{i}<\bar{k}$.

4. Suppose $k_{i}<k_{j}$. Then $\pi_{i} / \pi_{j}$ and $x_{i} / x_{j}$ are strictly decreasing in either transport cost $t$ or $\tau$.

\section{E. Empirical Implementation}

A central prediction of the theory is that there is a negative relationship between the average marginal cost of two direct competitors and their isolation in space, all else equal. Testing this prediction requires a measure of physical productivity and a measure of isolation.

Physical productivity must be measured directly. Inferring productivity from markups or revenues is insufficient because, as the theory predicts, markups and revenues themselves depend on remoteness in product or geographic space. If input and output data were available, one could construct a measure of total factor productivity that would be independent of isolation in space.

Testing this prediction also requires a measure of distance between either firm locations in geography (in a homogeneous good industry) or products in product characteristic space (in a differentiated good industry). It is not obvious how to extend the isolation result to two or more horizontal dimensions. Measuring isolation on the circumference of the circle is straightforward. When $n \geq 3$, each firm $i$ has exactly two neighbors, $i-1$ and $i+1$. Two natural measures of firm $i$ 's isolation 
are (i) $d_{i-1, i}+d_{i, i+1}$ and (ii) firm $i$ 's market share if all firms charge a common price. Measuring isolation in a multidimensional space is more difficult for two reasons. First, one needs to determine the set of firms that neighbor $i$. Second, given the set of firms that neighbor $i$, it is not obvious how to measure $i$ 's isolation.

One appealing measure of isolation is the size of each firm's market if all firms charge a common price. ${ }^{22}$ This is a price-independent measure of isolation that deals with each of the two issues mentioned above. It selects the set of firms that neighbor firm $i$. These are the firms that share a common market boundary; $i$ 's neighbors are the firms that would gain (lose) consumers from (to) firm $i$ if $i$ were to increase (decrease) its price from the common price. Given $i$ 's neighbors, it also provides a natural measure of isolation. This measure is an average of the distance between $i$ and each of its neighbors, weighted by the relative size of the common market boundary shared by $i$ and each neighbor.

There are clearly other, more structural measures of isolation that one could construct. ${ }^{23}$ These measures would depend on the structure imposed, although no more than the price-independent measure above relies on the assumption of a common price. One advantage of adding structure is that this provides microfoundations to justify the measure of isolation.

Another issue to confront when bringing the theory to data is the need to allow for different demand densities across markets. Syverson (2004) presents a selection model in which denser markets are associated with more productive firms. In denser markets more firms enter, making it easier for consumers to substitute from less productive firms to more productive firms. This induces high-cost firms to exit dense markets. He tests the model using data from the U.S. ready-mixed concrete industry and finds support for his predictions. Syverson's results suggest that denser markets tend to have more firms and more productive firms. This is an across-market prediction-across markets, more productive firms are less isolated than less productive firms-that moves in the opposite direction of my within-market result—within a market, more productive firms are more isolated than less productive firms.

It is a relatively straightforward exercise to deal with this issue by extending the two-stage game of this paper to incorporate an initial entry stage in the spirit of Hopenhayn (1992) and Syverson (2004). Such an extension justifies controlling for demand density in the regression of isolation on productivity. Each market $\rho$ is characterized by a demand density, $L(\rho)$. In each market there is a large set of ordered

${ }^{22}$ With a linear cost of transportation, all common prices will yield identical results.

${ }^{23}$ Feenstra and Levinsohn (1995), e.g., construct a measure of isolation when firms are differentiated in multiple dimensions, the cost of transportation is quadratic in distance, and firms optimally choose their prices. 
potential entrants: $1,2,3, \ldots$ The first stage is a sequential entry stage. The second and third stages are the location and price stages described in the two-stage game of this paper. In the sequential entry stage, potential entrant 1 moves first. She chooses whether or not to enter. If she chooses to enter, she pays a fixed cost $f_{e}>0$ to draw her marginal cost from a distribution $G(k)$. After drawing her cost $k_{i}$, she chooses whether to exit or produce. If she chooses to produce, she pays another fixed cost $f_{p}>0$ and moves to the subsequent location stage. If she exits, her game is over. All potential entrants $2,3, \ldots$ observe the first entrant's cost draw and actions. Then potential entrant 2 chooses whether or not to enter and so forth. After all potential entrants have played this first stage, the set of $n$ firms that chose to produce move to the location stage. ${ }^{24}$

Examples of industries in which spatial competition models have been tested include ready-mixed concrete (Syverson 2004; Collard-Wexler 2006), movie theaters (Davis 2006), motels (Mazzeo 2002), video retail (Seim 2006), gas stations (Houde 2006), and eyeglass retail (Watson 2004).

\section{Horizontal and Vertical Differentiation}

In this section I relax the assumption that all differentiation is horizontal by extending the model to incorporate both horizontal and vertical differentiation. ${ }^{25}$ Goods are vertically differentiated if all consumers have the same preference ranking of the products, all else equal. For instance, at the same price, all consumers prefer a higher-quality good. Goods are horizontally differentiated if consumers are unable to agree on an objective ranking of the products, all else equal. In what follows I allow for one dimension of horizontal differentiation and one dimension of vertical differentiation. However, it is straightforward to modify the model to incorporate arbitrarily many dimensions of vertical product differentiation.

Consumers.-A consumer located at point $z$ buying a unit of output from firm $i$ derives utility

$$
u(z, i)=v-1+q_{i}^{\gamma}-p_{i}-t D(z, i),
$$

where $q_{i}$ is the quality of firm $i$ s output and $\gamma \in[0,1)$. The preferences

\footnotetext{
${ }^{24}$ I consider sequential entry rather than simultaneous entry to ensure that, under parameter restrictions, there are always at least two firms that proceed to the location stage.

${ }_{25}$ Neven and Thisse (1990) consider a model in which two symmetric firms differentiate themselves vertically and horizontally. In this sense my work is an extension of theirs. However, the models differ in two other respects. First, they assume that product space is a unit interval, whereas I assume that it is a unit circumference. Second, the cost of transportation is quadratic in their model.
} 
above nest those of the model with no vertical differentiation. The utility functions are identical in the special case in which consumers do not place any value on quality: $\gamma=0$. According to this utility function, a given consumer, $z$, in a market with a finite set of producers, $N$, purchases one good from firm $i \in N$ if

$$
\begin{gathered}
i=\arg \min _{j \in N}\left\{p_{j}+t D(z, j)-q_{j}^{\gamma}\right\} \text { and } \\
p_{i}+t D(z, i)-q_{i}^{\gamma} \leq v-1 .
\end{gathered}
$$

If a consumer purchases one unit of output, she buys from the firm with the lowest location- and quality-adjusted price. I assume throughout that the valuation, $v$, is sufficiently high that all consumers in the market purchase a good in equilibrium.

There are three important assumptions implicit in equation (13). First, all consumers have the same marginal willingness to pay for quality. The existence and characterization results do not qualitatively depend on this assumption. ${ }^{26}$ I could add consumer heterogeneity in the marginal willingness to pay for quality by multiplying $q_{j}^{\gamma}$ in the definition of utility and in equation (13) by a consumer-specific preference parameter $\theta \in\left[\theta_{L}, \theta_{H}\right]$. Qualitative results would remain unchanged if these differences are not too large $\left(\theta_{L}+\varepsilon>\theta_{H}\right.$ for a sufficiently small $\left.\varepsilon\right)$ and if the distribution of $\theta$ is identical at each point in horizontal space. Second, utility is additive in the two dimensions of differentiation. This is a standard assumption in the differentiation literature (see, e.g., Neven and Thisse 1990; Anderson et al. 1992) that allows the two dimensions of differentiation to be identified. ${ }^{27}$ Finally, utility exhibits diminishing marginal returns to quality. The combination of this assumption and the assumption below that there are constant returns to scale in producing quality is isomorphic to another standard set of assumptions: that marginal utility is constant in quality and there are decreasing returns to scale in producing quality.

Firms.-Each firm $i$ is characterized by two cost parameters, $k_{i}$ and $c_{i}$. As before, the parameter $k_{i}$ denotes the marginal cost at which firm $i$ can produce a unit of zero-quality output. The parameter $c_{i}$ denotes the marginal cost of producing each unit of quality in each unit of output. A firm with vector of cost parameters $\left(k_{i}, c_{i}\right)$ that chooses quality level $q_{i}$ has a constant marginal cost of production equal to $k_{i}+c_{i} q_{i}$.

The game.-The game with vertical and horizontal differentiation is the same as the game with only horizontal differentiation, except that in the first stage, firms simultaneously choose both locations and qualities. I provide a full description of the game in Appendix B.

\footnotetext{
${ }^{26}$ The same, however, is not necessarily true of the uniqueness result.

${ }^{27}$ This is an argument made by Anderson et al. (1992).
} 
Market share and profit.-Consider a price vector $\mathbf{p}$ for which there exists an indifferent consumer between each pair of neighbors. It is straightforward to show that

$$
\begin{aligned}
x_{i} & =\frac{1}{2 t}\left[p_{i+1}+p_{i-1}-2 p_{i}+t\left(d_{i, i+1}+d_{i-1, i}\right)-q_{i+1}^{\gamma}-q_{i-1}^{\gamma}+2 q_{i}^{\gamma}\right], \\
\pi_{i} & =L x_{i}\left[p_{i}-\left(k_{i}+c_{i} q_{i}\right)\right]-L \tau\left(x_{i, i-1}^{2}+x_{i, i+1}^{2}\right) .
\end{aligned}
$$

Results.-The basic insights from the game with only horizontal differentiation remain unchanged when firms differentiate themselves both horizontally and vertically. Below I provide two propositions that generalize propositions 1 and 2 to the framework in which firms can differentiate themselves both horizontally and vertically.

Proposition 3. For any set of parameters $\theta \equiv(n, t, \tau, L), k \geq 0$, and $c>0$, there exists a $\phi(\theta, k, c)>0$ and $\varphi(\theta, k, c)>0$ such that if $k_{i} \times c_{i} \in[k, k+\phi(\theta, k)] \times[c, c+\varphi(\theta, k, c)]$ for all $i$, then there is a nonempty set $O^{* \prime} \subseteq \Omega^{n \prime}$ such that any $\omega \in O^{* \prime}$ is an SPNE. The set $O^{* \prime}$ has the following properties:

1. Strategies are pure along the equilibrium path for all $\omega \in O^{* \prime}$.

2. For any order of the firms around the circle there exists a corresponding $\omega \in O^{* \prime}$.

3. The distance between each pair of neighbors, firms $i$ and $i+1$, is

$$
d_{i, i+1}^{*}=\frac{1}{n}+\frac{2}{3 t+2 \tau}\left(\frac{\chi_{i}+\chi_{i+1}}{2}-\bar{\chi}\right),
$$

and firm $i$ 's price, quality, market share, and profit are

$$
\begin{aligned}
p_{i}^{*}= & (t+\tau)\left(\frac{1}{n}-\frac{2}{3 t+2 \tau} \bar{\chi}\right) \\
& +\frac{1}{3 t+2 \tau}\left\{[2(t+\tau)+t \gamma]\left(\frac{\gamma}{c_{i}}\right)^{\gamma /(1-\gamma)}+t k_{i}\right\}, \\
q_{i}^{*}= & \left(\frac{\gamma}{c_{i}}\right)^{1 /(1-\gamma)} \\
x_{i}^{*}= & \frac{1}{n}+\frac{2}{3 t+2 \tau}\left(\chi_{i}-\bar{\chi}\right), \\
\pi_{i}^{*}= & L t\left(x_{i}^{*}\right)^{2},
\end{aligned}
$$

where

$$
\chi_{i} \equiv(1-\gamma)\left(\frac{\gamma}{c_{i}}\right)^{\gamma /(1-\gamma)}-k_{i}, \quad \bar{\chi} \equiv \sum_{j=0}^{n-1} \chi_{j}
$$


Proposition 4. Suppose $\tau>0$. If

$$
k_{i} \times c_{i} \in[k, k+\phi(\theta, k)] \times[c, c+\varphi(\theta, k, c)]
$$

for all $i$, then $\omega$ is a strict SPNE if and only if $\omega \in O^{* \prime}$.

As in the model without vertical differentiation, there exists a set of SPNE in which strategies are pure along the equilibrium path and across which all economically relevant outcomes are identical. In this set of equilibria, a firm's price, quality, market share, and profit are independent of the productivities of its neighbors, conditional on the set of firms in the market. As in proposition 1, isolation adjusts to compensate a firm for the productivity of its neighbors. In particular, more productive firms are more isolated, all else equal. The key distinction is that productivity is now a function of both cost draws. The term $\chi_{i}$ is a measure of firm $i$ 's productivity: $\chi_{i}$ is strictly decreasing in $k_{i}$, is weakly decreasing in $c_{i}$, and is strictly decreasing in $c_{i}$ for all $\gamma>0$. Iso-productivity curves are convex to the origin in $(k, c)$ space.

Isolation, market share, and profit depend on $k_{i}$ and $c_{i}$ only through $\chi_{i}$. However, price and quality depend directly on $k_{i}$ and $c_{i}$. A firm's choice of quality depends on its vector of cost parameters only through $c_{i}$ : its quality is strictly decreasing in $c$ for all $\gamma>0$. Consider two firms, $i$ and $j$, where $c_{i}<c_{j}$ and $k_{i}=k_{j}$, and suppose that $\gamma>0$. Firm $i$ is the more productive firm. Firm $i$ chooses a higher quality than $j$. Finally, $i$ chooses to invest sufficiently more in the quality of its output such that $p_{i}>p_{j}$. That is, although firm $i$ is more productive than firm $j$, firm $i$ charges a higher price.

Note that $q_{i}^{*}$ is the arg min of the objective function $\left\{c_{i} q_{i}-q_{i}^{\gamma}\right\}^{28}$ This results from the fact that the two dimensions of differentiation are additively separable in preferences. This also demonstrates the fact, mentioned above, that identical results are obtained if the marginal utility of quality is constant and the marginal cost of quality is increasing. Finally, this highlights the fact that quality, unlike horizontal location, is not a particularly strategic variable in this setup. If quality were costless and firm $i$ could produce goods of exogenous quality $q_{i}$, then many qualitative results would remain unchanged. This suggests that the model can be adapted to incorporate an increasing fixed cost of producing quality, another standard assumption in the literature.

\section{Conclusions}

In this paper I solve a framework in which heterogeneous firms endogenously differentiate themselves horizontally, in product character-

\footnotetext{
${ }^{28}$ This is not a proof that the optimal quality is given by eq. (15) because quality is chosen in the first stage, not the second.
} 
istic or geographic space, and vertically, in quality space. The first central result is that when locations are endogenous, a firm's price, market share, and profit are affected by a competitor's marginal cost only through its impact on the average marginal cost in the market. This is true whether or not the two firms are direct competitors. This implies that, to the extent that relocation is costless, the impact of a reduction in one firm's marginal cost on a second firm's profit is independent of the proximity of the two firms. The intuition for this result is stark. Each firm has an incentive to locate at the center of its market share in order to minimize its shipping costs. When each firm prices optimally and locates at the center of its market share, indifferent consumers located between each pair of neighboring firms face the same location-adjusted prices. This implies that each firm's profit is independent of the productivities of its neighbors, given the set of firms in the market.

The second central result of the paper is that the distance between two direct competitors' products is strictly increasing in their average productivity: all else equal, more productive firms are more isolated. This implies that low-cost firms have greater market power because their competitors offer relatively poor substitutes. Hence, endogenous location provides a novel mechanism linking productivity to market share and profit.

This result provides insight into a set of economic and political phenomena. To the extent that not being isolated in product space is similar to locating in a less dense area of product space, it helps explain why inefficient firms tend to focus on small niches within larger markets. Additionally, the model can be viewed as a version of the HotellingDowns model in political science. In this case, the isolation result has interesting political implications. Suppose that, for historical reasons, some political parties have more support than others independent of their current policy positions. The result that more productive firms are more isolated then suggests that stronger political parties will be more isolated in policy space than their less competitive opposition.

Although the model yields tractable equilibrium path results, I have imposed several restrictions, three of which are especially important. I assume that demand is uniformly distributed over space, I limit the degree of asymmetry between firms, and I consider only one-dimensional horizontal differentiation. In a slightly different framework (Vogel 2007), I incorporate an arbitrary distribution of marginal costs. Extending the model to include variable demand density and more than one dimension of horizontal differentiation is an important task for future research. 
Appendix A

\section{Proofs}

Derivation of Equation (12)

Recall from equation (11) that firm's $i$ 's price stage reaction function in the auxiliary game is

$$
\frac{2(\tau+2 t)}{t+\tau} p_{i}=p_{i-1}+p_{i+1}+t\left(d_{i-1, i}+d_{i, i+1}\right)+\frac{2 t}{t+\tau} k_{i}
$$

This implies a system of $n$ first-order conditions

$$
A \mathbf{p}^{\prime}=\mathbf{b}^{\prime}
$$

where $A$ and $\mathbf{b}$ are defined in the text. The matrix $A$ is an invertible circulant matrix. A circulant matrix is one for which each row vector is rotated one element to the right relative to the preceding row vector. The inverse of a circulant matrix is circulant.

Define the matrix $H$ by $H \equiv A^{-1}$. The solution is given by $\mathbf{p}^{\prime}=H \mathbf{b}^{\prime}$, where $H$ is symmetric and circulant. Let $h_{i, k}$ denote the element of $H$ in the $(i+1)$ st row and $(k+1)$ st column (where $h_{i, k}$ is $\left.\bmod (n)\right)$. The row in which $h_{i, k}$ is located can be suppressed because $H$ is circulant. Instead, let $h(k)$ denote the $(k+1)$ st element in the first row of $H$. With this notation, $h_{i, k}=h(k-i)$. Firm $i$ 's price is $p_{i}=\sum_{k=0}^{n-1} h(k-i) b_{k}$.

CLAIM 1. In the auxiliary game, the solution to firm $i$ s price satisfies the following conditions:

1. If $n$ is even,

$$
\begin{aligned}
p_{i}= & \beta_{1}\left(d_{i-1, i}+d_{i, i+1}\right)+\cdots+\beta_{n / 2}\left[d_{i+1-(n / 2), i-(n / 2)}+d_{i-1+(n / 2), i+(n / 2)}\right] \\
& +\delta_{0}\left(k_{i}\right)+\delta_{1}\left(k_{i-1}+k_{i+1}\right)+\cdots+\delta_{n / 2}\left[k_{i-(n / 2)}\right]
\end{aligned}
$$

for all $i=0, \ldots, n-1$. If $n$ is odd,

$$
\begin{aligned}
p_{i}= & \beta_{1}\left(d_{i-1, i}+d_{i, i+1}\right)+\cdots+\beta_{(n+1) / 2}\left[d_{i-(n-1) / 2, i-(n+1) / 2}\right] \\
& +\delta_{0}\left(k_{i}\right)+\delta_{1}\left(k_{i-1}+k_{i+1}\right)+\cdots+\delta_{(n-1) / 2}\left[k_{i-(n-1) / 2}+k_{i+(n-1) / 2}\right]
\end{aligned}
$$

for all $i=0, \ldots, n-1$.

2. For all $n, \beta_{1}>\beta_{2}>\cdots$.

Proof. Part 1: In proving part 1 of claim 1, I do not focus on the distinction between the cases in which $n$ is odd and even. Instead, I prove the general form of $p_{i}$. I begin by focusing on the distance terms in $p_{i}$. With the symmetry of $H$, it can be shown that the coefficients on $d_{i+k, i+k+1}$ and $d_{i-k, i-k-1}$ in the solution to $p_{i}$ are identical. In the solution to $p_{i}$, the coefficient multiplying $d_{i+k, i+k+1}$ is $h(k)+h(k+1)$. Similarly, the coefficient multiplying $d_{i-k, i-k-1}$ is $h(-k)+h(-k-$ $1)$. Because $H$ is symmetric, $h(k)=h(-k)$ and $h(k+1)=h(-k-1)$. This implies that the distance terms enter the solution of $p_{i}$ in the form

$$
\beta_{1}\left(d_{i-1, i}+d_{i, i+1}\right)+\beta_{2}\left(d_{i-2, i-1}+d_{i+1, i+2}\right)+\cdots,
$$


where

$$
\beta_{k}=h(k-1)+h(k) .
$$

The term $[2 t /(t+\tau)] k_{i-j}$ appears only in $b_{i-j}$ and $[2 t /(t+\tau)] k_{i+j}$ appears only in $b_{i+j}$. In the solution to $p_{i}, b_{i-j}$ is multiplied by $h(-j)$ and $b_{i+j}$ is multiplied by $h(j)$. Moreover, $h(-j)=h(j)$ because $H$ is symmetric. Hence, the $[2 t /(t+\tau)] k$ terms enter the solution of $p_{i}$ in the form

$$
\delta_{0} k_{i}+\delta_{1}\left(k_{i-1}+k_{i+1}\right)+\cdots,
$$

where

$$
\delta_{j}=\frac{2 t}{t+\tau} h(j)
$$

This completes the proof of part 1 of claim 1 .

Part 2: In proving part 2 of claim 1, I focus on the case in which $n$ is odd. I do not work out the case in which $n$ is even, but the proof follows the same logic.

In the case in which $n$ is odd, part 2 of claim 1 states that $\beta_{k}>\beta_{k+1}$ for all $k \leq(n-1) / 2$. This is equivalent to $h(k-1)>h(k+1)$ for all $k \leq(n-1) / 2$. In order to prove part 2 of claim 1, I introduce one piece of new notation. Denote by $j^{\prime}$ the minimal number of elements separating $h(j)$ from $h(0)$ :

$$
j^{\prime} \equiv \begin{cases}j & \text { if } j \leq(n-1) / 2 \\ n-j & \text { if } j>(n-1) / 2\end{cases}
$$

I prove part 2 of claim 1 by proving that $h(j-i)>h(k-i)$ if and only if $j^{\prime}<k^{\prime}$.

Recall that $A H=I$ and consider only the first row of the identity matrix. This yields a system of equations

$$
\begin{gathered}
\frac{2(2 t+\tau)}{t+\tau} h(0)-h(1)-h(1)=1, \\
\frac{2(2 t+\tau)}{t+\tau} h(1)-h(0)-h(2)=0, \\
\ldots \\
\frac{2(2 t+\tau)}{t+\tau} h(j-1)-h(j-2)-h(j)=0, \\
\ldots \\
\frac{2(2 t+\tau)}{t+\tau} h(n-1)-h(n-2)-h(0)=0,
\end{gathered}
$$

which has a general solution

$$
h(j)=\zeta(j) h(0)-\nu(j)
$$

and the boundary condition

$$
h\left(\frac{n-1}{2}\right)=h\left(\frac{n+1}{2}\right)
$$


because $H$ is symmetric. Hence,

$$
\begin{aligned}
& \zeta(j)=\frac{2(2 t+\tau)}{t+\tau} \zeta(j-1)-\zeta(j-2), \\
& \nu(j)=\frac{2(2 t+\tau)}{t+\tau} \nu(j-1)-\nu(j-2)
\end{aligned}
$$

for all $j \geq 2$. Moreover, $\zeta(0)=1, \zeta(1)=(2 t+\tau) /(t+\tau)$, and $\nu(0)=0, \nu(1)=$ $\frac{1}{2}$. Using the boundary condition and equation (A4) to solve for $h(0)$ yields

$$
h(0)=\frac{\frac{3 t+\tau}{t+\tau} \nu\left(\frac{n-1}{2}\right)-\nu\left(\frac{n-3}{2}\right)}{\frac{3 t+\tau}{t+\tau} \zeta\left(\frac{n-1}{2}\right)-\zeta\left(\frac{n-3}{2}\right)} .
$$

It remains to solve the differential equation given in equation (A4). This is equivalent to solving the system

$$
x(y)-\frac{2(2 t+\tau)}{t+\tau} x(y-1)+x(y-2)=0
$$

given two different sets of initial conditions: (1) $x(0)=1$ and $x(1)=(2 t+$ $\tau) /(t+\tau)($ for $\zeta(y))$, and (2) $x(0)=0$ and $x(1)=\frac{1}{2}($ for $\nu(y))$.

The general solution to such a system is $x(y)=k r_{1}^{y}+j r_{2}^{y}$, where $r_{1}$ and $r_{2}$ are the roots of $x^{2}-[2(2 t+\tau) /(t+\tau)] x+1=0$. Let

$$
z \equiv \frac{2(2 t+\tau)}{t+\tau} \in(2,4]
$$

Then

$$
r_{1} \equiv \frac{1}{2}\left(z-\sqrt{z^{2}-4}\right) \in(0,1), \quad r_{2} \equiv \frac{1}{2}\left(z+\sqrt{z^{2}-4}\right)>1,
$$

implying

$$
x(y)=k\left(\frac{z-\sqrt{z^{2}-4}}{2}\right)^{y}+j\left(\frac{z+\sqrt{z^{2}-4}}{2}\right)^{y} .
$$

Solving for $\zeta(y)$ using the first set of initial conditions yields

$$
\zeta(y)=\frac{1}{2}\left[\left(\frac{z+\sqrt{z^{2}-4}}{2}\right)^{y}+\left(\frac{z-\sqrt{z^{2}-4}}{2}\right)^{y}\right] .
$$

Solving for $\nu(y)$ using the second set of initial conditions yields

$$
\nu(y)=\frac{1}{2 \sqrt{z^{2}-4}}\left[\left(\frac{z+\sqrt{z^{2}-4}}{2}\right)^{y}-\left(\frac{z-\sqrt{z^{2}-4}}{2}\right)^{y}\right] .
$$

Substituting equations (A6) and (A7) into equation (A2) yields a solution for 
$h(y)$ as a function of $h(0)$ :

$$
h(y)=\frac{1}{2 \sqrt{z^{2}-4}}\left\{\left(r_{2}\right)^{y}\left[h(0) \sqrt{z^{2}-4}-1\right]+\left(r_{1}\right)^{y}\left[h(0) \sqrt{z^{2}-4}+1\right]\right\} .
$$

Solving for $h(0)$ from equation (A5) using equations (A6) and (A7) yields an explicit solution for $h(0)$ :

$$
h(0)=\frac{\left(r_{2}\right)^{(n-3) / 2}\left[(z-1) r_{2}-1\right]-\left(r_{1}\right)^{(n-3) / 2}\left[(z-1) r_{1}-1\right]}{\sqrt{z^{2}-4}\left\{\left(r_{2}\right)^{(n-3) / 2}\left[(z-1) r_{2}-1\right]+\left(r_{1}\right)^{(n-3) / 2}\left[(z-1) r_{1}-1\right]\right\}} .
$$

Using the solution for $h(0)$ given in equation (A8) yields an explicit solution for $h(y)$ :

$$
h(y)=\frac{\left(r_{1}\right)^{y}\left(r_{2}\right)^{(n-3) / 2}\left[(z-1) r_{2}-1\right]-\left(r_{2}\right)^{y}\left(r_{1}\right)^{(n-3) / 2}\left[(z-1) r_{1}-1\right]}{\sqrt{z^{2}-4}\left\{\left(r_{2}\right)^{(n-3) / 2}\left[(z-1) r_{2}-1\right]+\left(r_{1}\right)^{(n-3) / 2}\left[(z-1) r_{1}-1\right]\right\}} .
$$

Finally, I prove that $h(y)$ is strictly decreasing in $y$ if and only if $y<n / 2$. Differentiating equation (A9) with respect to $y$ yields

$$
h^{\prime}(y)<0 \Leftrightarrow y<\frac{n-3}{2}+T(z),
$$

where

$$
T(z) \equiv \frac{\ln \left\{\left[\frac{(z-1) \frac{1}{2}\left(z+\sqrt{z^{2}-4}\right)-1}{(z-1) \frac{1}{2}\left(z-\sqrt{z^{2}-4}\right)-1}\right]\left[\frac{\ln \frac{1}{2}\left(z-\sqrt{z^{2}-4}\right)}{\ln \frac{1}{2}\left(z+\sqrt{z^{2}-4}\right)}\right]\right\}}{\ln \left[\frac{\frac{1}{2}\left(z+\sqrt{z^{2}-4}\right)}{\frac{1}{2}\left(z-\sqrt{z^{2}-4}\right)}\right]}
$$

The function $T(z)$ can be expressed as a function of $r_{1}$ and $r_{2}$, where $r_{1}$ and $r_{2}$ are the roots of the quadratic $x^{2}-z x+1$ :

$$
T(z)=\frac{\ln \left\{\left[\frac{(z-1) r_{2}-1}{(z-1) r_{1}-1}\right]\left(\frac{\ln r_{1}}{\ln r_{2}}\right)\right\}}{\ln \left(\frac{r_{2}}{r_{1}}\right)} .
$$

Substituting for $r_{1}$ using $r_{1}=1 / r_{2}$ yields

$$
T(z)=\frac{\ln \left[r_{2}\left(\frac{r_{2}-z r_{2}+1}{r_{2}-z+1}\right)\left(\frac{\ln r_{2}^{-1}}{\ln r_{2}}\right)\right]}{\ln r_{2}^{2}} .
$$

If $z>2$ (which it is), this is equivalent to

$$
T(z)=\frac{\ln r_{2}^{3}}{\ln r_{2}^{2}}
$$


because $\left(\ln r_{2}^{-1}\right) /\left(\ln r_{2}\right)=-1$ and $\left(r_{2}-z r_{2}+1\right) /\left(r_{2}-z+1\right)=-r_{2}^{2}$. This yields $T(z)=3 / 2$ for all $z>2$, proving that $h^{\prime}(y)<0$ if and only if $y<n / 2$. This completes the proof of part 2 of claim 1. QED

\section{Proof of Lemma 1}

Lemma 1 states that if $k_{i} \in\left[k, k+\phi_{1}(\theta, k)\right]$ for all $i$, then $\pi_{i}^{A *}=\pi_{i}^{*}$. Recall that $\phi_{1}(\theta, k) \equiv(3 t+2 \tau) /[2(n-1)]>0$ and that $\pi_{i}^{*}\left(\pi_{i}^{A *}\right)$ denotes firm $i$ 's profit in the real game (auxiliary game) if $\omega \in O^{*}$.

I begin by proving that the condition that $k_{i} \in\left[k, k+\phi_{1}(\theta, k)\right]$ for all $i$ is a sufficient condition under which $x_{i}^{*} \geq 0$ for all $i$ :

$$
\begin{aligned}
& x_{i}^{*} \geq 0 \Leftrightarrow \frac{1}{n}+\frac{2}{3 t+2 \tau}\left(\bar{k}-k_{i}\right) \geq 0 \\
\Leftrightarrow & k_{i} \leq \frac{1}{n-1} \sum_{j \neq i} k_{j}+\phi_{1}(\theta, k) .
\end{aligned}
$$

The right-hand side is minimized if $k_{j}=k$ for all $j \neq i$. Thus, if $\omega \in O^{*}$ and $k_{i} \in\left[k, k+\phi_{1}(\theta, k)\right]$ for all $i$, then $x_{i}^{*} \geq 0$ for all $i$.

If $\omega \in O^{*}$, then firms use pure strategies along the equilibrium path; moreover, no firm undercuts another in the real game because $x_{i}^{*} \geq 0$. When all firms use pure strategies and no firm undercuts another, each firm's profit is the same in the real game as it is in the auxiliary game. QED

Proof of Lemma 2

Lemma 2 states that there exists a $\phi_{2}(\theta, k)>0$ such that if $k_{j} \in\left[k, k+\phi_{2}(\theta, k)\right]$ for all $j$, then $\pi_{i}^{A *} \geq \pi_{i}^{A \prime}$ if $\tau \geq 0$ and $\pi_{i}^{A *}>\pi_{i}^{A \prime}$ if $\tau>0$.

Recall that $\pi_{i}^{A *}$ denotes firm $i$ 's profit in the auxiliary game if $\omega \in O^{*}$ and that $\pi_{i}^{A \prime}$ denotes firm $i$ s profit in the auxiliary game if it unilaterally deviates from $\omega \in O^{*}$ along the equilibrium path. There are four steps to the proof. In the first step I prove that if $k_{j} \in\left[k, k+\phi_{2}(\theta, k)\right]$ for all $j$ and firm $i$ sets a price sufficiently low that there exists a firm $j \neq i$ for which $x_{j}=0$ in the auxiliary game, then $\pi_{i}^{A *}>\pi_{i}^{A \prime}$. In the second and third steps I consider deviations in which all firms $j \neq i$ have positive market shares in the auxiliary game. If firm $i$ deviates in the location stage, it can deviate either "locally" or "drastically." Firm $i$ deviates locally if it locates in the segment between the two firms between which it is supposed to locate, but not in the exact location specified by equation (9). Firm $i$ deviates drastically if it locates in any other segment. In step 2, I prove that if firm $i$ deviates locally and all firms $j \neq i$ have positive market shares in the auxiliary game, then $i$ 's profit is strictly (weakly) less than its equilibrium profit if $\tau>0(\tau=0)$. In step 3, I prove that if firm $i$ deviates drastically and all firms $j \neq i$ have positive market shares in the auxiliary game, then $i$ 's profit is strictly less than its equilibrium profit. In the final step, I prove that if firm $i$ unilaterally deviates while locating between firms $h$ and $j$, then there exists no SPNE to the auxiliary game in which $x_{g}=0$ for any firm $g \neq h, i, j$.

STEP 1. There exists a $\phi_{2, a}(\theta, k)>0$ such that if $k_{j} \in\left[k, k+\phi_{2, a}(\theta, k)\right]$ for all $j$ and firm $i$ sets a price sufficiently low that its neighbor $i+1$ (or $i-1)$ supplies no consumers in the auxiliary game, then $\pi_{i}^{A *}>\pi_{i}^{A \prime}$.

Proof. Suppose that firm $i$ sets a price sufficiently low that its neighbor, firm $i+1$, supplies no consumers in the auxiliary game, $x_{i+1}^{A}=0: x_{i+1}^{A}=0$ if and only 
if $p_{i+1} \geq(1 / 2)\left(p_{i}+p_{i+2}\right)+(t / 2) D_{i+1}$, where $D_{i+1} \equiv d_{i, i+1}+d_{i+1, i+2}$. Substituting $p_{i+1}$ from equation (11) into the above condition that $x_{i+1}^{A}=0$ yields $p_{i}+$ $p_{i+2} \leq 2 k_{i}-t D_{i}$. This weak inequality together with equation (11) implies $p_{i+1} \leq$ $k_{i+1}$. Thus, $x_{i+1}^{A}=0$ if and only if $p_{i+1} \leq k_{i+1}$. Hence, $p_{i} \leq k_{i+1}$.

If firms are symmetric and firm $i$ sets a price sufficiently low that its neighbor, firm $i+1$ (or $i-1)$, supplies no consumers in the auxiliary game, then $\pi_{i}^{A} *>$ $\pi_{i}^{A \prime}$. By a continuity argument there exists a $\phi_{2, a}(\theta, k)>0$ such that if $k_{j} \in[k$, $\left.k+\phi_{2, a}(\theta, k)\right]$ for all $j$, then $\pi_{i}^{A *}>\pi_{i}^{A \prime}$ if firm $i$ sets a price sufficiently low that its neighbor, $i+1$ (or $i-1$ ), supplies no consumers in the auxiliary game. QED

STEP 2. If firm $i$ deviates locally and each firm supplies a positive mass of consumers in the auxiliary game, then firm $i$ 's profit in the auxiliary game is strictly (weakly) less than its equilibrium profit if $\tau>0(\tau=0)$.

Proof. Recall that auxiliary profit is $\pi_{i}=L x_{i}\left(p_{i}-k_{i}\right)-L \tau\left(x_{i, i-1}^{2}+x_{i, i+1}^{2}\right)$ and that firm $i$ s price in the auxiliary game is

$$
\begin{aligned}
p_{i}= & \beta_{1}\left(d_{i-1, i}+d_{i, i+1}\right)+\beta_{2}\left(d_{i-2, i-1}+d_{i+1, i+2}\right)+\cdots \\
& +\delta_{0} k_{i}+\delta_{1}\left(k_{i-1}+k_{i+1}\right)+\cdots
\end{aligned}
$$

If firm $i$ follows its equilibrium strategy, denote its variables by an asterisk (*). If it (unilaterally) deviates locally, denote its variables by a prime ('). Define $\Delta \pi_{i} \equiv \pi_{i}^{\prime}-\pi_{i}^{*}$ :

$$
\frac{1}{L} \Delta \pi_{i}=x_{i}^{\prime}\left(p_{i}^{\prime}-k_{i}\right)-x_{i}^{*}\left(p_{i}^{*}-k_{i}\right)-\tau\left[\left(x_{i, i-1}^{\prime}\right)^{2}+\left(x_{i, i+1}^{\prime}\right)^{2}-2\left(\frac{1}{2} x_{i}^{*}\right)^{2}\right] .
$$

I first show that $x_{i}^{\prime}=x_{i}^{*}$ and $p_{i}^{\prime}=p_{i}^{*}$. Then I prove that $\left(x_{i, i-1}^{\prime}\right)^{2}+\left(x_{i, i+1}^{\prime}\right)^{2}>$ $2\left(\frac{1}{2} x^{*}\right)^{2}$.

That $p_{i}^{\prime}=p_{i}^{*}$ in the auxiliary game is clear from the equation for firm $i$, price. To prove that $x_{i}^{\prime}=x_{i}^{*}$, suppose that firm $i$ moves $\delta \in\left(0, d_{i-1, i}\right)$ units toward firm $i-1$ from its equilibrium location. Firm $(i-1)$ 's price decreases by $\delta\left(\beta_{1}-\beta_{2}\right)$ and firm $(i+1)$ 's price increases by $\delta\left(\beta_{1}-\beta_{2}\right)$. Hence, $p_{i-1}+p_{i+1}$ is independent of firm $i$ 's location for any local deviation. Firm $i$ 's market share is a function of $p_{i-1}+p_{i+1}, p_{i}$, and $d_{i-1, i}+d_{i, i+1}$. Each of these terms remains constant for any local deviation by firm $i$. Therefore, $x_{i}^{\prime}=x_{i}^{*}$ in the auxiliary game.

Because $x_{i}^{\prime}\left(p_{i}^{\prime}-k_{i}\right)=x_{i}^{*}\left(p_{i}^{*}-k_{i}\right)$, it is clear that $\Delta \pi_{i}<0$ if and only if $\left(x_{i, i-1}^{\prime}\right)^{2}+\left(x_{i, i+1}^{\prime}\right)^{2}>2\left(\frac{1}{2} x^{*}\right)^{2}$ and $\tau>0$. If firm $i$ deviates locally by moving $\delta \in$ $\left(0, d_{i-1, i}\right)$ units toward firm $i-1$, then $x_{i}^{\prime}=x_{i}^{*}, x_{i, i-1}^{\prime}<\frac{1}{2} x^{*}$, and $x_{i, i+1}^{\prime}>\frac{1}{2} x^{*}$. This implies that $\left(x_{i, i-1}^{\prime}\right)^{2}+\left(x_{i, i+1}^{\prime}\right)^{2}>2\left(\frac{1}{2} x^{*}\right)^{2}$. In the auxiliary game if firm $i$ deviates locally and $\tau>0(\tau=0)$, then its profit is strictly less than (equal to) its equilibrium profit. QED

STEP 3. There exists a $\phi_{2, b}(\theta, k)>0$ such that if $k_{j} \in\left[k, k+\phi_{2, b}(\theta, k)\right]$ for all $j$, firm $i$ deviates drastically, and each firm supplies a positive mass of consumers in the auxiliary game, then firm $i$ 's profit in the auxiliary game is strictly less than its equilibrium profit.

Proof. Suppose that all firms are symmetric and that firm $i$ drastically deviates. The drastic deviation that yields the greatest profit for firm $i$ is to locate between firms $i-2$ and $i-1$ (or equivalently between firms $i+1$ and $i+2$ ). When firm $i$ locates between firms $i-1$ and $i-2$, its profit in the auxiliary game is $\pi_{i}=$ $L x_{i}\left(p_{i}-k_{i}\right)-L \tau\left(x_{i, i-1}^{2}+x_{i, i-2}^{2}\right)$. Given that firm $i$ locates between firms $i-1$ and $i-2$, it maximizes its profit by locating such that $x_{i, i-1}=x_{i, i-2}$ (see step 2 in the 
proof of proposition 2). Denote by $d \in(0,1 / n)$ the distance from $i-1$ at which $x_{i, i-1}=x_{i, i-2}$.

Suppose that firm $i$ locates at a distance $d$ from firm $i-1$. According to claim 1 , firm $i$ 's price in the auxiliary game is $p_{i}=p_{i}^{*}-(t / n)\left(\beta_{1}-\beta_{2}\right)<p^{*}$. Firm $(i-$ $1)$ 's price is $p_{i-1}=p^{*}+d t\left(\beta_{1}-\beta_{2}\right)$ and firm $(i-2)$ 's price is $p_{i-2}=p^{*}-$ $d t \beta_{1}-[(1 / n)-d] t \beta_{2}+(1 / n) t \beta_{3}$.

Solving for $d$ by equating $x_{i,-1}=x_{i, i-2}$ yields

$$
d=\left(\frac{1-\beta_{2}+\beta_{3}}{1+\beta_{1}-\beta_{2}}\right) \frac{1}{2 n}<\frac{1}{2 n} .
$$

At these prices, firm $i$ 's market share is $x_{i}=x_{i}^{*}-(1 / 2 n)\left(1-2 \beta_{1}+3 \beta_{2}-\beta_{3}\right)$ and

$$
\frac{1}{L} \Delta \pi_{i}=\left(x_{i}-x_{i}^{*}\right)\left[p_{i}^{*}-k_{i}-\frac{\tau}{2}\left(x_{i}^{*}+x_{i}\right)\right]-x_{i} \frac{t}{n}\left(\beta_{1}-\beta_{2}\right) .
$$

The term $\Delta \pi_{i}$ is strictly negative if $p_{i}^{*}-k_{i}-(\tau / 2)\left(x_{i}^{*}+x_{i}\right) \geq 0$ and $x_{i}^{*} \geq x_{i}$. Under the condition that $x_{i}^{*} \geq x_{i}$, we know that $p_{i}^{*}-k_{i}-(\tau / 2)\left(x_{i}^{*}+x_{i}\right) \geq 0$ is satisfied because $p_{i}^{*}=[(t+\tau) / n]+k$ and $2 x_{i}^{*} \geq x_{i}^{*}+x_{i}$.

Thus, it only remains to prove that $x_{i}^{*} \geq x_{i}$ :

$$
x_{i}^{*} \geq x_{i} \Leftrightarrow 1-2 \beta_{1}+3 \beta_{2}-\beta_{3} \geq 0 .
$$

The inequality $1-2 \beta_{1}+\beta_{2} \geq 0$ is a sufficient condition under which $x_{i}^{*} \geq x_{i}$ holds because $2 \beta_{2}-\beta_{3}>0$. From the derivation of equation (12) recall that $\beta_{1}=$ $h(0)+h(1)$ and $\beta_{2}=h(1)+h(2)$. This implies

$$
\begin{gathered}
2 \beta_{1}-\beta_{2}= \\
\frac{\left(r_{2}\right)^{(n-3) / 2}\left[(z-1) r_{2}-1\right]\left(2+r_{1}-r_{1}^{2}\right)+\left(r_{1}\right)^{(n-3) / 2}\left[(z-1) r_{1}-1\right]\left(r_{2}^{2}-2-r_{2}\right)}{\sqrt{z^{2}-4}\left\{\left(r_{2}\right)^{(n-3) / 2}\left[(z-1) r_{2}-1\right]+\left(r_{1}\right)^{(n-3) / 2}\left[(z-1) r_{1}-1\right]\right\}} .
\end{gathered}
$$

Note that $2 \beta_{1}-\beta_{2}$ is decreasing in $n$ for all $n \geq 3$ (which is the range over which drastic deviations are possible). Therefore, $2 \beta_{1}(n=3)-\beta_{2}(n=3) \leq 1$ is a sufficient condition for $x_{i}^{*} \geq x_{i}$, where $2 \beta_{1}(n=3)-\beta_{2}(n=3)=2(z-$ 1) $/[(z-1) z-2]$. Finally,

$$
\tau<t \Rightarrow z \in(3,4] \Rightarrow \frac{2(z-1)}{(z-1) z-2}<1 .
$$

Therefore, the assumption that $\tau<t$ is sufficient to ensure that if firm $i$ deviates drastically in the auxiliary game and all firms are symmetric, then firm $i$ 's profit is strictly less than its equilibrium profit. Then a continuity argument implies that there exists a $\phi_{2, b}(\theta, k)>0$ such that if $k_{j} \in\left[k, k+\phi_{2, b}(\theta, k)\right]$ for all $j$ and firm $i$ deviates drastically in the auxiliary game, then firm $i$, s profit is strictly less than its equilibrium profit. QED

STEP 4. There exists a $\phi_{2, c}(\theta, k)>0$ such that if $k_{j} \in\left[k, k+\phi_{2, c}(\theta, k)\right]$ for all $j$ and firm $i$ unilaterally deviates while locating between firms $h$ and $j$, then there exists no SPNE to the auxiliary game in which $x_{g}=0$ for any firm $g \neq h, i, j$.

Proof. If all firms are symmetric and $i$ unilaterally deviates, then the distance between firm $g$ and both of its neighbors is $1 / n$. From here it is straightforward to prove that if all firms are symmetric, then no firm would charge a price sufficiently low that $x_{g}=0$. Then apply a continuity argument. QED

Let $\phi_{2}(\theta, k) \equiv \min _{i=a, b, c}\left\{\phi_{2, i}(\theta, k)\right\}$. The proof of lemma 2 follows directly from 
steps 1-4. If firm $i$ deviates in the location stage in such a way that there exists a firm $j$ with $x_{j}=0$, then $\pi_{i}^{A *}>\pi_{i}^{A \prime}$. If firm $i$ deviates in the location stage in such a way that there exists no firm $j$ with $x_{j}=0$, then $i$ deviates either locally or drastically. In steps 2 and 3 I prove that if firm $i$ deviates locally (step 2) or drastically (step 3) while locating between firms $h$ and $j$ and $x_{g}>0$ for all $g \neq$ $h, i, j$, then firm $i$ 's profit is no greater than its equilibrium profit (and is strictly less if $\tau>0$ ). It remains only to prove that if firm $i$ unilaterally deviates while locating between firms $h$ and $j$, then in any SPNE to the auxiliary game, $x_{g}>0$ for all $g \neq h, i, j$. This is proved in step 4 .

Therefore, there exists a $\phi_{2}(\theta, k)>0$ such that if $k_{j} \in\left[k, k+\phi_{2}(\theta, k)\right]$ for all $j$, then $\pi_{i}^{A *} \geq \pi_{i}^{A \prime}$ if $\tau \geq 0$ and $\pi_{i}^{A *}>\pi_{i}^{A \prime}$ if $\tau>0$.

\section{Proof of Lemma 3}

According to lemma 3 , if $k_{i} \in\left[k, k+\phi_{3}(\theta, k)\right]$ for all $i$, then either $\pi_{i}^{A \prime} \geq E\left[\pi_{i}^{\prime}\right]$ or $\pi_{i}^{*}>E\left[\pi_{i}^{\prime}\right]$. Recall that $\pi_{i}^{A \prime}\left(E\left[\pi_{i}^{\prime}\right]\right)$ denotes firm $i$ 's profit in the auxiliary game (expected profit in the real game) if it unilaterally deviates from $\omega \in O^{*}$ along the equilibrium path. I prove lemma 3 in four steps.

STEP 1. Suppose that all firms locate according to equation (9) in the location stage and all firms $j \neq i$ choose their price according to equation (10). There exists a $\phi_{3, a}(\theta, k)>0$ such that if $k_{h} \in\left[k, k+\phi_{3, a}(\theta, k)\right]$ for all $h$, then $\pi_{i}^{*}>E\left[\pi_{i}^{\prime}\right]$.

Proof. Suppose that all firms locate according to equation (9) in the location stage and that all firms $j \neq i$ choose their price according to equation (10) in the price stage. Clearly $\pi_{i}^{\prime}<\pi_{i}^{*}$ if firm $i$ deviates by choosing any price $p_{i}^{\prime} \neq p_{i}^{*}$ at which it does not undercut either of its neighbors. If all firms have identical marginal costs, then firm $i$ 's profit is bounded above by $(-3 L \tau) /\left(2 n^{2}\right)$ if it undercuts its neighbors. By a continuity argument, there exists a $\phi_{3, a}(\theta, k)>0$ such that if $k_{j} \in\left[k, k+\phi_{3, a}(\theta, k)\right]$ for all $j$, no firm $i$ will undercut its neighbors when all firms locate according to equation (9) and all firms $j \neq i$ price according to equation (10). QED

STEP 2. If there exists a pure strategy equilibrium in which no firm is undercut, then $E\left[\pi_{i}^{\prime}\right]=\pi_{i}^{A \prime}$.

Proof. The proof follows from the fact that when firms play pure strategies and no firm is undercut, then profit in the real game equals profit in the auxiliary game. Note that when firms play pure strategies, $E\left[\pi_{i}^{\prime}\right]=\pi_{i}^{\prime}$. QED

STEP 3. Fix a profile of locations in which each firm $j \neq i$ locates as prescribed by $\omega \in O^{*}$. Suppose that at least one firm is undercut with probability one. There exists a $\phi_{3, b}(\theta, k)>0$ such that if $k_{i} \in\left[k, k+\phi_{3, b}(\theta, k)\right]$ for all $i$, then $\pi_{i}^{*}>E\left[\pi_{i}^{\prime}\right]$.

Proof. Recall that a firm is undercut if it supplies no consumers in equilibrium. A firm is undercut with probability one if for any realization of prices its market share is zero. Note that it is possible for firm $i$ to undercut firm $j$ for certain realizations without undercutting firm $j$ with probability one.

Fix the profile of locations and suppose that firm $i$ undercuts firm $j$ with probability one. ${ }^{29}$ In such an equilibrium firm $i$ must charge a price no greater than $k_{j}-t d_{i, j}$. Suppose that all firms are identical and have marginal cost $k$. This implies that firm $i$ 's price must be no greater than $k$ in order for it to undercut

${ }^{29}$ The result is obvious in the case in which $i$ is undercut with probability one. Moreover, I have already shown that if $i$ or either of its neighbors is not undercut with probability one, then no firm will be undercut with probability one. 
firm $j$ with probability one. At any such price firm $i$ 's profit per sale is bounded above by zero. This implies that $\pi_{i}^{*}>0 \geq E\left[\pi_{i}^{\prime}\right]$ when all firms have identical marginal costs. By a continuity argument, there exists a $\phi_{3, b}(\theta, k)>0$ such that if $k_{j} \in\left[k, k+\phi_{3, b}(\theta, k)\right]$ for all $j$, then $\pi_{i}^{*}>E\left[\pi_{i}^{\prime}\right]$. QED

STEP 4. If the profile of locations is such that there exists no pure strategy equilibrium and in the mixed strategy equilibrium to the subgame no firm is undercut with probability one, then $\pi_{i}^{A \prime} \geq E\left[\pi_{i}^{\prime}\right]$.

Proof. Suppose that the profile of locations is such that there exists no pure strategy equilibrium. According to Reny (1999), there exists a mixed strategy equilibrium in all price stage subgames. Suppose additionally that in the equilibrium to the subgame no firm is undercut with probability one.

Denote by $m_{i}\left(M_{i}^{\prime}\right)$ the inf (sup) price over which firm $i$ mixes with positive probability for all $i=0, \ldots, n-1$, if such a price exists. Note that $m_{i}$ exists because $p_{i} \geq 0$. However, $M_{i}^{\prime}$ may not exist. Define

$$
M_{i} \equiv \begin{cases}M_{i}^{\prime} & \text { if } M_{i}^{\prime} \leq v \\ v & \text { if } M_{i}^{\prime}>v\end{cases}
$$

where $v$ equals consumers' reservation value. In what follows I focus, without loss of generality, on an equilibrium in which each firm mixes over a bounded support, where $p_{i} \leq v$. Firm $i$ is indifferent between mixing over the support with supremum $M_{i}$ and the supremum $M_{i}^{\prime}$ because any price $p \geq M_{i}$ yields zero profit independent of the prices other firms charge. Moreover, firm $i$ 's best response is identical for any price $p_{j} \geq M_{j}$ that any competitor $j \neq i$ charges.

In step 4, I focus on subgames for which no firm is undercut with probability one in equilibrium. This implies that the following condition holds:

$$
M_{i}<\min \left\{M_{i-1}+t d_{i-1, i}, M_{i+1}+t d_{i, i+1}\right\} .
$$

According to the condition in equation (A11), when firm $i-1(i+1)$ charges the sup of the support of prices over which it mixes with positive probability, $M_{i-1}\left(M_{i+1}\right)$, it cannot undercut firm $i$.

Clatm 2. Denote by $P_{i}$ firm $i$ 's best response to $p_{k}=M_{k}$ for all $k \neq i$ given that firm $i$ undercuts no firms. Then $P_{i} \geq M_{i}$.

Proof. Suppose that $p_{k}=M_{k}$ for all $k \neq i$ and, to obtain a contradiction, that $P_{i}<M_{i}$. When $p_{k}=M_{k}$ for all $k \neq i$, firm $i$ 's best response is unique over the range of prices at which it does not undercut another firm (and equals $P_{i}$ ) because its profit function is continuous and quasi-concave over this range. Hence, if firm $i$ charges the price $P_{i}$, it earns strictly more profit than if it charges the price $M_{i}$ when $p_{k}=M_{k}$ for all $k \neq i$.

The price $P_{i}$ yields firm $i$ profit that is never less than that yielded by the price $M_{i}$ for any profile of prices $p_{k} \leq M_{k}$ for all $k \neq i$ because prices are strategic complements. This implies that firm $i$ does not mix with positive probability over $M_{i}$ in equilibrium, contradicting the assumption that $P_{i}<M_{i}$. QED

I use claim 2 to prove the following claim.

Clatm 3. $\quad M_{i} \leq a_{i}$ for all $i$, where $a_{i}$ is the price firm $i$ would charge in the auxiliary game.

Proof. To obtain a contradiction, suppose that there exists a nonempty set of firms $J \equiv\left\{k \in N \mid M_{k}>a_{k}\right\}$. Denote by $J^{c}$ the complement of $J$ in $N$. Because prices are strategic complements, proving a contradiction will be most difficult in the case in which $J^{c}$ is empty. Accordingly, let $J^{c}=\varnothing$.

Suppose that each firm $j \in J$ charges price $M_{j}$. No firm undercuts another firm because all satisfy equation (A11). The vector of prices $\left(a_{0}, \ldots, a_{n-1}\right)$ found in claim 1 is the unique solution to the system of $n$ reaction functions in the 
auxiliary game when no firm undercuts another. This implies that when all firms $j \neq i$ charge $M_{j}$, there exists at least one firm $i$ for which $P_{i}<M_{i}$, which contradicts claim 2. If no such firm existed, then either $\left(a_{0}, \ldots, a_{n-1}\right)$ would not be a solution to the system of $n$ reaction functions in the auxiliary game or it would not be the unique solution. However, the vector $\left(a_{0}, \ldots, a_{n-1}\right)$ is the unique solution. This contradiction implies that the set $J$ must be empty, proving claim 3. QED

I use claim 3 to prove step 4 of lemma 3.

Fix the locations of all $n$ firms. Let $\pi_{i}\left(p_{j}=M_{j} \forall j\right)$ denote firm $i$ 's profit if each firm charges the price that is the upper bound over which it mixes. Recall that $\pi_{i}^{A} \equiv \pi_{i}^{A}\left(p_{j}=a_{j} \forall j\right)$ denotes firm $i$ 's profit if each firm charges its equilibrium price in the auxiliary game. Let $E\left[\pi_{i}\left(p_{i}=M_{i}\right)\right]$ denote firm $i$ 's expected profit if it charges the price $M_{i}$ and let $E\left[\pi_{i}\right]$ denote firm $i$ s expected profit.

First, in order for firm $i$ to assign positive probability to $M_{i}$, it must be that $E\left[\pi_{i}\right]=E\left[\pi_{i}\left(p_{i}=M_{i}\right)\right]$. Second, consider the case in which the realization of firm $i$ 's price is $M_{i}$. When firm $i$ sets the price $M_{i}$, it is unable to undercut either of its two neighbors and its profit is increasing in $p_{i-1}$ and $p_{i+1}$. Thus, $E\left[\pi_{i}\left(p_{i}=\right.\right.$ $\left.\left.M_{i}\right)\right] \leq \pi_{i}\left(p_{j}=M_{j} \forall j\right)$.

It remains to prove that $\pi_{i}\left(p_{j}=M_{j} \forall j\right) \leq \pi_{i}^{A}$. According to claim 3, which states that $M_{j} \leq a_{j}$ for all $j, \pi_{i}^{A}\left(p_{j}=M_{j} \forall j\right) \leq \pi_{i}^{A}\left(p_{i}=M_{i}, p_{j}=a_{j} \forall j \neq i\right)$ because firm $i$ 's profit is increasing in the prices of its competitors. Finally, $\pi_{i}^{A}\left(p_{i}=M_{i}\right.$, $\left.p_{j}=a_{j} \forall j \neq i\right) \leq \pi_{i}^{A}$ because $a_{i}$ is firm $i$ s best response in the auxiliary game when $p_{j}=a_{j} \forall j \neq i$. Thus, $\pi_{i}^{A}\left(p_{j}=M_{j} \forall j\right) \leq \pi_{i}^{A}$.

I have demonstrated that if the profile of locations is such that there exists no pure strategy equilibrium and if in the mixed strategy equilibrium to the subgame no firm is undercut with probability one, then the following relationship must hold: $E\left[\pi_{i}\right]=E\left[\pi_{i}\left(p_{i}=M_{i}\right)\right] \leq \pi_{i}\left(p_{j}=M_{j} \forall j\right) \leq \pi_{i}^{A}$. Hence, $E\left[\pi_{i}\right] \leq \pi_{i}^{A}$. This concludes the proof of step 4. QED

Proof of lemma 3. Let $\phi_{3}(\theta, k) \equiv \min _{i=a, b}\left\{\phi_{3, i}(\theta, k)\right\}$. Suppose that $k_{i} \in[k$, $\left.k+\phi_{3}(\theta, k)\right]$ for all $i$. There are three possible cases:

1. There exists a pure strategy equilibrium to the price stage game in which no firm is undercut. In this case $\pi_{i}^{A \prime}=E\left[\pi_{i}^{\prime}\right]$ according to step 1 and step 2.

2. At least one firm is undercut with probability one. In this case $\pi_{i}^{*}>E\left[\pi_{i}^{\prime}\right]$ according to step 3 .

3. There exists no pure strategy equilibrium to the price stage game, and in the equilibrium to the subgame no firm is undercut with probability one. In this case $\pi_{i}^{A \prime} \geq E\left[\pi_{i}^{\prime}\right]$ according to step 4 .

Combining steps $1-4$ yields the conclusion that if $k_{i} \in\left[k, k+\phi_{3}(\theta, k)\right]$ for all $i$, then either $\pi_{i}^{A \prime} \geq E\left[\pi_{i}^{\prime}\right]$ or $\pi_{i}^{*}>E\left[\pi_{i}^{\prime}\right]$. This proves lemma 3. QED

\section{Proof of Proposition 2}

Proposition 2 states that if $\tau>0$ and $k_{i} \in[k, k+\phi(\theta, k)]$ for all $i$, then $\omega$ is a strict SPNE if and only if $\omega \in O^{*}$.

In all that follows let $\tau>0$ and $k_{i} \in[k, k+\phi(\theta, k)]$. The proof proceeds in two steps. In the first, I prove that if $\omega \in O^{*}$, then $\omega$ is a strict SPNE. In the second, I prove that $\omega$ is a strict SPNE only if $\omega \in O^{*}$.

Step 1: Recall that $\pi_{i}^{*}\left(\pi_{i}^{A *}\right)$ denotes firm $i$ 's profit in the real game (auxiliary game) if $\omega \in O^{*}$ and $\pi_{i}^{A \prime}\left(E\left[\pi_{i}^{\prime}\right]\right)$ denotes firm $i$ 's profit in the auxiliary game (expected profit in the real game) if $i$ unilaterally deviates from $\omega \in O^{*}$ along the equilibrium path. 
Combining lemmas 1,2 , and 3 yields the relationship $\pi_{i}^{*}>E\left[\pi_{i}^{\prime}\right]$. This provides the result that if $\omega \in O^{*}$, then $\omega$ is a strict SPNE.

Step 2: To prove that if $\omega$ is a strict SPNE then $\omega \in O^{*}$, I require the following three claims.

Claim 4. If a pure strategy equilibrium in prices exists, then this is the unique mixed strategy equilibrium in prices.

Proof. Choose an arbitrary price stage subgame for which a pure strategy Nash equilibrium exists. Suppose that a nondegenerate mixed strategy equilibrium exists, and let $m_{i}\left(M_{i}\right)$ denote the inf (sup) of the support over which firm $i$ randomizes. Recall that $a_{i}$ is the price that firm $i$ charges in the pure strategy equilibrium and that $M_{i} \leq a_{i}$ for all $i$ according to claim 3. Note that $M_{i} \leq a_{i}$ for all $i$ implies that no firm is ever undercut in the mixed strategy equilibrium. This follows from an argument similar to the one used in step 1 in the proof of lemma 3; if $M_{i} \leq a_{i}$ for all $i, k_{i} \in[k, k+\phi(\theta, k)]$, and firm $i$ charges a price $p_{i}$ sufficiently low to undercut firm $i+1$ when $p_{i+1}=M_{i+1}$, then $i$ 's profit is strictly negative whenever it charges $p_{i}$. It can be shown that over the relevant range of prices, $\left[m_{i}, M_{i}\right]$, the price subgame is a supermodular game.

According to theorem 5 in Milgrom and Roberts (1990), for each player $i$ there exists largest and smallest serially undominated strategies $\bar{p}_{i}$ and $p_{i}$, where the strategy profiles $\left(\bar{p}_{i} ; i \in N\right)$ and $\left(p_{i} ; i \in N\right)$ are pure Nash equilibrium profiles. We have already proved that if a pure strategy equilibrium exists in the price subgame, then it is the unique pure strategy equilibrium. Thus, if a pure strategy equilibrium exists, then $\bar{p}_{i}=p_{i}$ for all $i$, proving that the pure strategy equilibrium is the unique mixed strategy equilibrium. ${ }^{30}$ QED

Claim 5. Suppose that $\omega$ is a strict SPNE in which no firm is undercut. Choose an arbitrary firm $i$ and fix the locations of firms $j \neq i$ as prescribed by $\omega$. There is an open $\varepsilon$-ball around the location prescribed by $\omega$ to firm $i$ such that if $i$ locates in this open $\varepsilon$-ball, then there exists a strict equilibrium in the price stage subgame.

Proof. Let $\omega$ be a strict SPNE in which no firm is undercut. Suppose that all firms locate as prescribed by $\omega$ and choose an arbitrary firm $j$. Suppose that all firms $k \neq j$ set prices as prescribed by $\omega$. Denote by $\pi_{j}^{U}$ the maximum profit that firm $i$ earns if $i$ undercuts any of its neighbors if all other firms $k \neq j$ set prices that are optimal in the auxiliary game; and recall that $\pi_{j}^{A}$ denotes firm $j$ s profit if all firms, including $j$, set prices that are optimal in the auxiliary game. The fact that $\omega$ is a strict SPNE implies that $v_{j} \equiv \pi_{j}^{A}-\pi_{j}^{U}>0$ for all $j$.

Choose an arbitrary firm $i$ and suppose that all firms $k \neq i$ locate as prescribed by $\omega$. Suppose that, for any $\varepsilon>0$, if $i$ unilaterally deviates in the location stage by locating $\varepsilon$ from the location prescribed by $\omega$, then no strict equilibrium exists in the resulting price stage subgame. This requires that after any such $\varepsilon$ unilateral deviation, there exists a firm $j$ that satisfies $v_{j} \leq 0$. However, $v_{j}$ is continuous in the vector of firm locations since both $\pi_{j}^{A}$ and $\pi_{j}^{U}$ are. This contradicts the assumption that $\omega$ is a strict SPNE. QED

The following claim makes use of the two claims above.

Claim 6. $\quad x_{i, i-1}=x_{i, i+1}$ for all $i$ in every strict SPNE.

Proof. Let $\omega$ be a strict SPNE. Suppose that if all firms follow strategies as prescribed by $\omega$, then there exists a firm $i$ for which $x_{i, i-1} \neq x_{i, i+1}$; without loss of generality, suppose that $x_{i, i-1}>x_{i, i+1}$. Suppose that firm $i$ unilaterally deviates

${ }^{30}$ Another, similar, approach is to prove directly that $m_{i} \geq a_{i}$; the proof is similar to the proof that $M_{i} \leq a_{i}$. The two results $m_{i} \geq a_{i}$ and $M_{i} \leq a_{i}$ give $m_{i}=M_{i}=a_{i}$. This proves the claim. 
in the location stage but locates within a distance $\varepsilon$ of the location prescribed by $\omega$. Then according to the above two claims, there exists an $\varepsilon>0$ such that in the resulting price stage subgame the unique mixed strategy equilibrium is a pure strategy equilibrium. In what follows I prove that firm $i$ could increase its profit by unilaterally deviating in the location stage (moving toward firm $i-1)$.

An SPNE is strict only if strategies are pure along the equilibrium path. This implies that in any strict SPNE, prices in the real game are identical to prices in the auxiliary game. Hence, I can reduce the two-stage game to a one-stage game by solving for prices in the second stage of the auxiliary game and substituting these directly into the location stage. Fix the locations of firms $i-1$ and $i+1$ and consider the optimal location for firm $i$. Define $\pi_{i}\left(d_{i-1, i}, \mathbf{k}\right)$ as firm $i$ 's profit given $d_{i-1, i}$, differentiate $\pi_{i}$ with respect to $d_{i-1, i}$, and denote the resulting first-order condition by $f_{i}$ :

$$
f_{i}=2 L \tau\left[\left(x_{i, i+1}\right) \frac{\partial x_{i, i+1}}{\partial d_{i-1, i}}+\left(x_{i, i-1}\right) \frac{\partial x_{i, i-1}}{\partial d_{i-1, i}}\right],
$$

where

$$
\frac{\partial x_{i, i+1}}{\partial d_{i-1, i}}=\frac{-\partial x_{i, i-1}}{\partial d_{i-1, i}}
$$

The first-order condition is satisfied if and only if $x_{i, i+1}=x_{i, i-1}$. The second-order condition for maximization is satisfied for all $d_{i-1, i}$ at which a pure strategy equilibrium exists in the resulting price stage subgame. Hence, there exists an $\varepsilon>0$ unilateral deviation by firm $i$ (toward firm $i-1$ ) that strictly increases firm $i$ 's profit (by increasing $x_{i, i+1}$ and decreasing $x_{i, i-1}$ ). This contradicts the assumption that $\omega$ is a strict SPNE. QED

I now proceed to prove that $\omega$ is a strict SPNE only if $\omega \in O^{*}$. Suppose that $\omega^{\prime}$ is a strict SPNE. Because $\omega^{\prime}$ is a strict SPNE, $x_{i, i-1}=x_{i, i+1}$ for all $i$ :

$$
x_{i, i-1}=x_{i, i+1} \Leftrightarrow \eta_{i, i-1}=\eta_{i, i+1},
$$

where $\eta_{i, i-1} \equiv p_{i-1}+t d_{i-1, i}$ and $\eta_{i, i+1} \equiv p_{i+1}+t d_{i, i+1}$. According to claim 1, in the equilibrium to any price stage subgame in the auxiliary game,

$$
\begin{aligned}
\eta_{i, i-1}= & \beta_{1}\left[d_{i-2, i-1}+\left(1+\frac{t}{\beta_{1}}\right) d_{i-1, i}\right]+\beta_{2}\left(d_{i-3, i-2}+d_{i, i+1}\right)+\cdots \\
& +\delta_{0} k_{i-1}+\delta_{1}\left(k_{i-2}+k_{i}\right)+\cdots
\end{aligned}
$$

and

$$
\begin{aligned}
\eta_{i, i+1}= & \beta_{1}\left[\left(1+\frac{t}{\beta_{1}}\right) d_{i, i+1}+d_{i+1, i+2}\right]+\beta_{2}\left(d_{i-1, i}+d_{i+2, i+3}\right)+\cdots \\
& +\delta_{0} k_{i+1}+\delta_{1}\left(k_{i}+k_{i+2}\right)+\cdots
\end{aligned}
$$

Substituting the solutions for $\eta_{i, i-1}$ and $\eta_{i, i+1}$ into equation (A12) yields

$$
\boldsymbol{\gamma}_{i} \mathbf{d}^{\prime}=g_{i}
$$

for the appropriately defined vector $\gamma_{i}$ and scalar $g_{i}$, each of which is fixed given 
the order in which the firms locate. The combination of the $n$ equations (A13), one for each firm, yields the system

$$
\Gamma \mathbf{d}^{\prime}=\mathbf{g}^{\prime}
$$

where the $(i+1)$ st row of $\Gamma$ is $\gamma_{i}$ and the $(i+1)$ st row of $\mathbf{g}^{\prime}$ is $g_{i}$. Either all vectors $\mathbf{d}$, no vectors $\mathbf{d}$, or a unique vector $\mathbf{d}$ solves the system in equation (A14).

The vector $\mathbf{d}^{*}$ characterized by equation (9) solves the system in equation (A14). Either this is the unique solution or all vectors $\mathbf{d}$ solve the system. I have already shown that if firm $i$ unilaterally and "locally" deviates, then $x_{i, i-1} \neq$ $x_{i, i+1}$, which implies that the vector of locations that results from such a deviation does not solve the system in equation (A14). Therefore, $\mathbf{d}^{*}$ characterized by equation (9) is the unique solution to the system in equation (A14).

If firm locations satisfy equation (9), then there is a unique pure strategy equilibrium in the pricing subgame. In this equilibrium firms choose prices according to equation (10). Hence, if $\omega^{\prime}$ is a strict SPNE, then $\omega^{\prime} \in O^{*}$. This completes the proof of proposition 2. QED

\section{Proofs of Propositions 3 and 4}

The proofs of propositions 3 and 4 are very similar to the proofs of propositions 1 and 2. In this section I focus exclusively on proving that for any profile of locations in which there exists no firm $j$ such that $x_{j}=0$ in the auxiliary game, firm $i$ 's optimal quality in the auxiliary game is given by $q_{i}^{*}$ from equation (15).

Following a strategy very similar to the one used to derive equation (12), it can be shown that when there is both horizontal and vertical differentiation, firm $i$ 's best response in prices in the auxiliary game is

$$
\begin{aligned}
p_{i}= & \beta_{1}\left(d_{i-1, i}+d_{i, i+1}\right)+\beta_{2}\left(d_{i-2, i-1}+d_{i+1, i+2}\right)+\cdots \\
& +\psi_{0}\left(q_{i}^{\gamma}\right)+\psi_{1}\left(q_{i-1}^{\gamma}+q_{i+1}^{\gamma}\right)+\cdots \\
& +\delta_{0}\left(k_{i}+q_{i} c_{i}\right)+\delta_{1}\left(k_{i-1}+q_{i-1} c_{i-1}+k_{i+1}+q_{i+1} c_{i+1}\right)+\cdots,
\end{aligned}
$$

where

$$
\delta_{0}-\delta_{1}=\psi_{1}-\psi_{0}+1
$$

In what follows I prove that for any profile of locations in which every firm has a positive market share in the auxiliary game, firm $i$ 's optimal quality in the auxiliary game is

$$
q_{i}=\left(\frac{\psi_{1}-\psi_{0}+1}{\delta_{0}-\delta_{1}}\right)^{1 /(1-\gamma)}\left(\frac{\gamma}{c_{i}}\right)^{1 /(1-\gamma)}
$$

which equals $q_{i}^{*}$ according to equation (A16). Differentiating profit with respect to $q_{i}$ yields

$$
\frac{d \pi_{i}}{d q_{i}}=L\left[2 x_{i}(t+\tau) \frac{\partial x_{i}}{\partial q_{i}}+2 \tau\left(x_{i, i+1} \frac{\partial x_{i, i+1}}{\partial q_{i}}+x_{i, i-1} \frac{\partial x_{i, i-1}}{\partial q_{i}}\right)\right],
$$


where

$$
\begin{aligned}
\frac{\partial x_{i, i+1}}{\partial q_{i}} & =\frac{1}{2 t}\left(\frac{\partial p_{i+1}}{\partial q_{i}}-\frac{\partial p_{i}}{\partial q_{i}}+\gamma q_{i}^{\gamma-1}\right), \\
\frac{\partial x_{i, i-1}}{\partial q_{i}} & =\frac{1}{2 t}\left(\frac{\partial p_{i-1}}{\partial q_{i}}-\frac{\partial p_{i}}{\partial q_{i}}+\gamma q_{i}^{\gamma-1}\right), \\
\frac{\partial x_{i}}{\partial q_{i}} & =\frac{1}{2 t}\left(\frac{\partial p_{i+1}}{\partial q_{i}}+\frac{\partial p_{i-1}}{\partial q_{i}}-2 \frac{\partial p_{i}}{\partial q_{i}}+2 \gamma q_{i}^{\gamma-1}\right) .
\end{aligned}
$$

According to equation (A15), $\partial p_{i+1} / \partial q_{i}=\partial p_{i-1} / \partial q_{i}=\psi_{1} \gamma q_{i}^{\gamma-1}+\delta_{1} c_{i}$ and $\partial p_{i} / \partial q_{i}=\psi_{0} \gamma q_{i}^{\gamma-1}+\delta_{0} c_{i}$. Therefore,

$$
\frac{1}{2} \frac{\partial x_{i}}{\partial q_{i}}=\frac{\partial x_{i, i+1}}{\partial q_{i}}=\frac{\partial x_{i, i-1}}{\partial q_{i}}=\frac{1}{2 t}\left[\gamma q_{i}^{\gamma-1}\left(\psi_{1}-\psi_{0}+1\right)+c_{i}\left(\delta_{1}-\delta_{0}\right)\right] .
$$

This implies that

$$
\begin{gathered}
\frac{d \pi_{i}}{d q_{i}}=2 L x_{i}(2 t+3 \tau) \frac{\partial x_{i, i+1}}{\partial q_{i}}=0 \Leftrightarrow \\
\gamma q_{i}^{\gamma-1}\left(\psi_{1}-\psi_{0}+1\right)+c_{i}\left(\delta_{1}-\delta_{0}\right)=0 \Leftrightarrow \\
q_{i}=\left(\frac{\psi_{1}-\psi_{0}+1}{\delta_{0}-\delta_{1}}\right)^{1 /(1-\gamma)}\left(\frac{\gamma}{c_{i}}\right)^{1 /(1-\gamma)} .
\end{gathered}
$$

According to equation (A16), $q_{i}=\left(\gamma / c_{i}\right)^{1 /(1-\gamma)}$. This is equivalent to $q_{i}=q_{i}^{*}$.

\section{Appendix B}

\section{Vertical and Horizontal Differentiation}

The game.-There are $n \geq 2$ firms that play a two-stage game of complete information. In the first stage, the location and quality stage, firms simultaneously choose locations on the circumference of the circle $z_{i} \in[0,1)$ and qualities $q_{i} \in[0, \infty)$, where $\mathbf{q} \equiv\left(q_{0}, \ldots, q_{n-1}\right)$. In the second stage, the price stage, firms observe locations and qualities and simultaneously choose their prices $p_{i} \in[0, \infty]$. A pure strategy is a choice of location and quality as well as a mapping from locations and qualities, $\mathbf{z} \times \mathbf{q}$, into prices. A strategy for firm $i, \omega_{i}$, specifies a joint probability distribution over locations and qualities as well as a probability distribution over prices as a function of locations and qualities. Denote firm $i$ 's strategy space by $\Omega_{i}^{\prime}$. Let $\Omega^{n \prime} \equiv \Omega_{0}^{\prime} \times \cdots \times \Omega_{n-1}^{\prime}$ and denote $\omega \in$ $\Omega^{n \prime}$ by a strategy vector.

Let $\vartheta^{\prime}(\mathbf{z} \times \mathbf{q}, \mathbf{p})$ be the set of locations at which consumers buy from firm $i$. Firm $i$ s profit from selling to the consumers in locations $\vartheta^{\prime}(\mathbf{z} \times \mathbf{q}, \mathbf{p})$ is

$$
\pi_{i}=L \int_{z \in \vartheta^{\prime}(\mathbf{z} \times \mathbf{q}, \mathbf{p})}\left[p_{i}-k_{i}-2 \tau D(z, i)\right] d z .
$$

The function $\vartheta^{\prime}(\mathbf{z} \times \mathbf{q}, \mathbf{p})$ 's dependence on $(\mathbf{z} \times \mathbf{q}, \mathbf{p})$ is described below.

The solution concept employed is that of SPNE: each $z_{i} \times q_{i}$ in the support of $\omega_{i}$ is optimal given the strategies of the other players and each price in the support of $\omega_{i}$ is optimal in each subgame given $\mathbf{z} \times \mathbf{q}$ and the strategies of the 
other players in that subgame. Finally, I restrict attention to equilibria in which no firm randomizes over $z \times q$ along the equilibrium path.

\section{References}

Anderson, Simon P., Andre de Palma, and Jacques-François Thisse. 1992. Discrete Choice Theory of Product Differentiation. Cambridge, MA: MIT Press.

Collard-Wexler, Allan. 2006. "Plant Turnover and Demand Fluctuations in the Ready-Mix Concrete Industry." Working paper, Center Econ. Studies, U.S. Census Bureau.

d'Aspremont, Claude, Jean J. Gabszewicz, and Jacques-François Thisse. 1979. “On Hotelling's 'Stability in Competition.'” Econometrica 47 (5): 1145-50.

Davis, Peter. 2006. "Spatial Competition in Retail Markets: Movie Theaters." Rand J. Econ. 37 (4): 964-83.

Economides, Nicholas. 1989. "Symmetric Equilibrium Existence and Optimality in Differentiated Product Markets." J. Econ. Theory 47 (1): 178-94.

Feenstra, Robert C., and James A. Levinsohn. 1995. "Estimating Markups and Market Conduct with Multidimensional Product Attributes." Rev. Econ. Studies 62 (1): 19-52.

Fudenberg, Drew, and Jean Tirole. 2000. Game Theory. Cambridge, MA: MIT Press.

Hopenhayn, Hugo A. 1992. "Entry, Exit, and Firm Dynamics in Long Run Equilibrium." Econometrica 60 (5): 1127-50.

Houde, Jean-François. 2006. "Spatial Differentiation in Retail Markets for Gasoline." Working paper, Univ. Wisconsin-Madison.

Kats, Amoz. 1995. "More on Hotelling's Stability in Competition." Internat. J. Indus. Organization 13 (1): 89-93.

Lancaster, Kelvin J. 1979. Variety, Equity, and Efficiency: Product Variety in an Industrial Society. New York: Columbia Univ. Press.

Mazzeo, Michael J. 2002. "Product Choice and Oligopoly Market Structure." Rand J. Econ. 33 (2): 221-42.

Melitz, Mark J., and Gianmarco I. P. Ottaviano. 2005. "Market Size, Trade, and Productivity.” Working Paper no. 11393, NBER, Cambridge, MA.

Milgrom, Paul, and John Roberts. 1990. "Rationalizability, Learning, and Equilibrium in Games with Strategic Complementarities." Econometrica 58 (6): $1255-77$.

Neven, Damien J., and Jacques-François Thisse. 1990. "On Quality and Variety Competition." In Economic Decision-Making: Games, Econometrics and Optimisation: Contributions in Honour of Jacques H. Dreze, edited by Jean J. Gabszewicz, Jean-François Richard, and Laurence A. Wolsey. Amsterdam: North-Holland.

Osborne, Martin J., and Carolyn Pitchik. 1987. "Equilibrium in Hotelling's Model of Spatial Competition." Econometrica 55 (4): 911-22.

Pesendorfer, Martin. 2002. "Retail Sales: A Study of Pricing Behavior in Supermarkets." J. Bus. 75 (1): 33-66.

Pinkse, Joris, Margaret E. Slade, and Craig Brett. 2002. "Spatial Price Competition: A Semiparametric Approach.” Econometrica 70 (3): 1111-53.

Reny, Philip J. 1999. "On the Existence of Pure and Mixed Strategy Nash Equilibria in Discontinuous Games.” Econometrica 67 (5): 1029-56.

Salop, Steven C. 1979. "Monopolistic Competition with Outside Goods." Bell J. Econ. 10 (1): 141-56.

Seim, Katja. 2006. "An Empirical Model of Firm Entry with Endogenous ProductType Choices.” Rand J. Econ. 37 (3): 619-40. 
Syverson, Chad. 2004. "Market Structure and Productivity: A Concrete Example." J.P.E. 112 (6): 1181-1222.

Vogel, Jonathan. 2007. "Spatial Price Discrimination with Heterogeneous Firms." Manuscript, Univ. California, Los Angeles.

Watson, Randal. 2004. "Product Variety and Competition in the Retail Market for Eyeglasses." Manuscript, Univ. Texas at Austin. 